\title{
A new velocity field for Greece: Implications for the kinematics and dynamics of the Aegean
}

\author{
M. A. Floyd,${ }^{1,2}$ H. Billiris, ${ }^{3}$ D. Paradissis,${ }^{3}$ G. Veis,${ }^{3}$ A. Avallone, ${ }^{4}$ P. Briole,${ }^{5}$ \\ S. McClusky, ${ }^{6}$ J.-M. Nocquet, ${ }^{7}$ K. Palamartchouk, ${ }^{1}$ B. Parsons, ${ }^{1}$ and P. C. England ${ }^{1}$ \\ Received 15 October 2009; revised 18 June 2010; accepted 1 July 2010; published 6 October 2010.
}

[1] A new set of geodetic velocities for Greece and the Aegean, derived from 254 surveymode and continuous GPS sites, is used to test kinematic and dynamic models for this area of rapid continental deformation. Modeling the kinematics of the Aegean by the rotation of a small number (3-6) of blocks produces RMS misfits of $\sim 5 \mathrm{~mm} \mathrm{yr}^{-1}$ in the southern Aegean and western Peloponnese, indicating significant internal strain within these postulated blocks. It is possible to fit the observed velocities to within $2-3 \mathrm{~mm} \mathrm{yr}^{-1}$ (RMS) by models that contain 10 or more blocks, but many such models can be found, with widely varying arrangements of blocks, that fit the data equally well provided that the horizontal dimension of those blocks is not larger than 100-200 km. A continuous field of velocity calculated from the GPS velocities by assuming that strain rates are homogeneous on the scale of $\sim 120 \mathrm{~km}$ fits the observed velocities to better than $2-3 \mathrm{~mm} \mathrm{yr}^{-1}$ (RMS), with systematic misfits, representing more localized strain, confined to a region approximately $100 \times 100 \mathrm{~km}$ in size around the western Gulf of Corinth. This velocity field accounts for the major active tectonic features of Greece and the Aegean, including the widespread north-south extensional deformation and the distributed strike-slip deformation in the NE Aegean and western Greece. The T axes of earthquakes are aligned with the principal axes of elongation in the geodetic field, major active normal fault systems are perpendicular to those axes, and $\sim 90 \%$ of the large earthquakes in this region during the past 120 years took place within the areas in which the geodetic strain rate exceeds 30 nanostrain $\mathrm{yr}^{-1}$. These observations suggest that the faulting within the upper crust of the Aegean region is driven by forces that are coherent over a scale that is significantly greater than $100 \mathrm{~km}$. It is likely that those forces arise primarily from differences in gravitational potential energy within the lithosphere of the region.

Citation: Floyd, M. A., et al. (2010), A new velocity field for Greece: Implications for the kinematics and dynamics of the Aegean, J. Geophys. Res., 115, B10403, doi:10.1029/2009JB007040.

\section{Introduction}

[2] The Aegean region is one of the most rapidly deforming parts of the continents, with velocity differences of 20 $40 \mathrm{~mm} \mathrm{yr}^{-1}$ developed across its $700 \times 700 \mathrm{~km}$ extent. The region has a prominent place in the study of continental tectonics because there are good records of seismic activity and Quaternary faulting; many of the active faults have

\footnotetext{
${ }^{1}$ Department of Earth Sciences, University of Oxford, Oxford, UK.

${ }^{2}$ Now at Department of Earth Sciences, University of California, Riverside, California, USA.

${ }^{3}$ Higher Geodesy Laboratory, National Technical University, Athens, Greece.

${ }^{4}$ Istituto Nationale di Geofisica e Vulcanologia, Centro Nazionale Terremoti, Rome, Italy.

${ }^{5}$ Ecole Normale Supérieure, Laboratoire de Géologie, Paris, France.

${ }^{6}$ Department of Earth, Atmospheric, and Planetary Sciences, Massachusetts Institute of Technology, Cambridge, Massachusetts, USA

${ }^{7}$ CNRS-GéoAzur, University of Nice, Valbonne, France.

Copyright 2010 by the American Geophysical Union. 0148-0227/10/2009JB007040
}

limestone footwalls that resist erosion, so form prominent scarps [e.g., Goldsworthy and Jackson, 2000, 2001], and the record of large earthquakes $\left(M_{w} \geq 5.8\right)$ is reasonably complete over the past 120 years [Ambraseys and Jackson, 1990; Jackson and McKenzie, 1988; Shaw and Jackson, 2010]. These observations, along with geodetic measurements of crustal displacements on the time scales between a century [Billiris et al., 1991; Davies et al., 1997; Veis et al., 1992] and a decade [e.g., Avallone et al., 2004; Briole et al., 2000; Clarke et al., 1998; Hollenstein et al., 2008; Kahle et al., 2000; McClusky et al., 2000; Reilinger et al., 2006] have contributed importantly to the development of ideas about the kinematics and dynamics of continental deformation.

[3] Recent studies of the kinematics of the region, particularly those using the Global Positioning System (GPS) to measure crustal velocities, have interpreted the tectonics in terms of the relative motions of rigid microplates or blocks [e.g., McClusky et al., 2000; Reilinger et al., 2006; Nyst and Thatcher, 2004]. Early studies of the kinematics, however, which were based largely upon the evidence from earth- 
quake focal mechanisms and active faulting, recognized the relative motion of rigid bodies, or microplates, but also emphasized that significant parts of the region deform in a diffuse fashion [e.g., Jackson and McKenzie, 1988; McKenzie, 1970, 1972]; see Le Pichon et al. [1995] for a comparable view based on geodetic velocities. Other geodetic studies of the kinematics suggested that a large proportion of the crust of the region is straining at several tens of nanostrain (nstrain) per year [e.g., Billiris et al., 1991; Clarke et al., 1998; Davies et al., 1997; Hollenstein et al., 2008].

[4] Analysis of this distributed strain has generated several important insights into continental deformation, for example the relations between normal faulting, elevated heat flux and subsidence are now understood in terms of distributed thinning of the lithosphere [McKenzie, 1978a, 1978b]. Equally, the relations among slip vectors of earthquakes, paleomagnetic rotations, and finite displacements on faults can be explained by analyzing how crustal blocks accommodate a velocity field that is coherent over a length scale much larger than the blocks themselves [e.g., Jackson et al., 1995; McKenzie and Jackson, 1983, 1986; Taymaz et al., 1991].

[5] The predominantly westward-to-southwestward movement of Turkey and Greece relative to Eurasia reflects the difference in gravitational potential energy between the thick crust in eastern Turkey and the thin crust of the ocean floor of the eastern Mediterranean [McKenzie, 1972]; additional forces resulting from the sinking of the subducting slab or from instabilities of the lithosphere may also influence this motion [Le Pichon, 1982; McKenzie, 1978b]. The dynamics are linked to the kinematics through the question of whether the continental lithosphere as a whole deforms in response to these forces, in which case the distribution of strain rates should reflect the large-scale distribution of stress within the lithosphere [e.g., Hatzfeld et al., 1997a; McKenzie, 1978b; Sonder and England, 1989], or whether deformation is confined to a few narrow weak zones, in which case motions of the lithosphere will resemble those of a set of rigid microplates [e.g., McClusky et al., 2000; Reilinger et al., 2006; Nyst and Thatcher, 2004].

[6] We present a new velocity field for the region of Greece and the Aegean Sea (Figure 1) based on 254 surveymode and continuous GPS (CGPS) sites, using it to test models for the deformation based on the relative motion of between 4 and 15 rigid blocks, and upon a smoothly varying field of strain rate.

\section{GPS Data and Analysis}

[7] We combined 38 GPS surveys undertaken between 1991 and 2004 by the National Technical University of Athens (NTUA) in association with the Institut de Physique du Globe de Paris (IPGP), Massachusetts Institute of Technology (MIT), and the University of Oxford. The results of several of these surveys have been published separately [Avallone et al., 2004; Briole et al., 2000; Clarke et al., 1998; McClusky et al., 2000; Reilinger et al., 2006], and our purpose here is to create a dense, unified and extensive regional data set from these studies in a common frame of reference. In addition, we included data from networks of continuously recording sites across Greece operated by NTUA and the Department of Earth Sciences, University of Oxford, since
2002, and by the National Observatory of Athens since 2006; results from those sites with at least 3 years of data are reported.

[8] The analysis was carried out using the GAMIT/ GLOBK 10.35 software suite [Herring et al., 2009] in three steps. In the first step, raw data were processed to produce loosely constrained daily solutions of site positions. The contributing institutions carried out this step separately for the surveys in which they were involved. At IPGP, orbits and Earth orientation parameters were held fixed to their IGS final and IERS Bulletin B values, respectively. In solutions obtained at MIT and Oxford, adjustments to the orbital parameters, and to values of Earth orientation parameters, were estimated simultaneously with site coordinates during the processing.

[9] In the second step, daily survey and continuous solutions were expressed in ITRF2005 [Altamimi et al., 2007] using a six-parameter Helmert transformation to derive the time series of position at each site. Position outliers were identified at this step and removed. The average repeatabilities for each survey are $1.3,0.9,3.4 \mathrm{~mm}$ on the east, north, and vertical component, respectively. All daily solutions for each survey were combined into a single loosely constrained position solution. Because the survey solutions obtained at IPGP were processed with fixed orbital and Earth orientation parameters, they had smaller formal uncertainties than the other solutions. We therefore rescaled their associated variance-covariance matrices so that their weights were similar to those of our other surveys carried out at similar times.

[10] For the continuous stations, outliers were automatically removed using criteria similar to those of Wdowinski et al. [1997]. Observations having formal positional uncertainty greater than $5 \mathrm{~mm}$ in either horizontal component or $10 \mathrm{~mm}$ in the vertical were removed. The time series were then fit, by a weighted linear regression, to a model consisting of a linear trend, annual and semiannual sinusoidal variations for each component, and offsets for each epoch at which a major change of equipment occurred. Observations whose misfits were greater than three times the weighted root-mean-square (RMS) value for the fit were then also removed.

[11] The cleaned continuous time series were analyzed for the presence of time-dependent (colored) noise, using the CATS software [Williams, 2008]. The time series for each component was assumed to contain a power law noise [e.g., Mandelbrot and Van Ness, 1968] and its spectral index was estimated. For most of the continuous time series, the spectral index was found to be between -1 and -2 , indicating the presence of colored noise.

[12] In the third step, the combined solutions for each survey and the cleaned daily solutions for each continuous site were passed through a Kalman filter (GLOBK [Herring et al., 2009]) to estimate a consistent set of coordinates and velocities with their associated variance-covariance matrix. Velocities of sites that lie within $500 \mathrm{~m}$ of one another were equated. Reference frame constraints were applied at this step to express our solution in the ITRF2005 [Altamimi et al., 2007].

[13] Because GLOBK uses a random walk process noise model, we calculated the magnitude of the random walk process noise that would predict the same velocity uncer- 


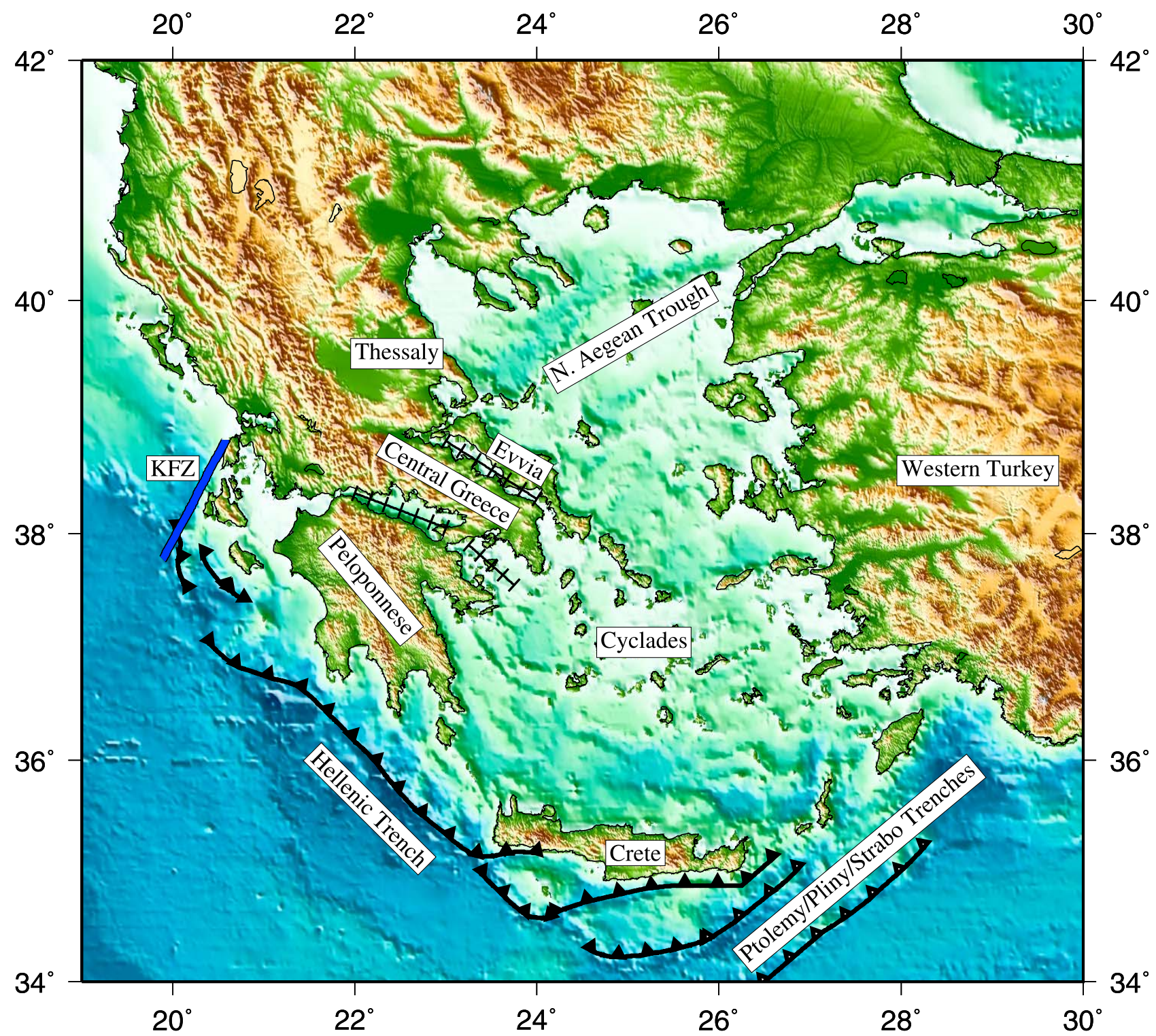

Figure 1. Setting of the Aegean. Labels show places referred to in the text. Lines with teeth show the locations of reverse faults of the Hellenic Trench system. To the west of $25^{\circ} \mathrm{E}$, convergence between ocean floor of the Nubian plate and the Aegean lithosphere is approximately normal to the Hellenic Trench. East of $25^{\circ} \mathrm{E}$, there is an important component of oblique relative motion (Figure 3); the trenches here are often referred to as the Ptolemy, Pliny, and Strabo trenches. None of these trenches represents the plate boundary; they are probably the surface expressions of intraplate deformation [e.g., Shaw and Jackson, 2010]. Blue line marked KFZ shows the Kefalonia right-lateral strike-slip fault zone. The major gulfs referred to in the text are shown by crossed lines: the Gulf of Evvia is between Evvia and central Greece; the Gulf of Corinth is between the Peloponnese and central Greece; and the Gulf of Saros lies to the SE of the eastern end of the Gulf of Corinth.

tainty as was derived from the CATS analysis, using the uncertainties, $\sigma$ (generated by the CATS analysis), in the individual velocity components for the continuous sites to estimate the magnitude, $b$, of the equivalent random walk noise, through the relation:

$$
b=\sigma \sqrt{T},
$$

where $T$ is the length of the individual time series [Zhang et al., 1997, equation (2)]. The mean value of $b$ for the set of all Aegean CGPS sites and the proximal IGS and EPN sites contained in our processing is $0.3 \mathrm{~mm} \sqrt{\mathrm{yr}}^{-1}$ for horizontal components and $2 \mathrm{~mm} \sqrt{\mathrm{yr}}^{-1}$ for the vertical. For the surveymode sites, we added random walk noise using those mean values of $b$.

[14] A number of earthquakes having $M_{w} \geq 6$ occurred within the network during the period of observation. All survey-mode sites within $30 \mathrm{~km}$ of the $M_{w} 6.5,26$ July 2001 , Skyros earthquake and the $M_{w} 6.3,14$ August 2003, Lefkada earthquake were last occupied before the respective earth- 

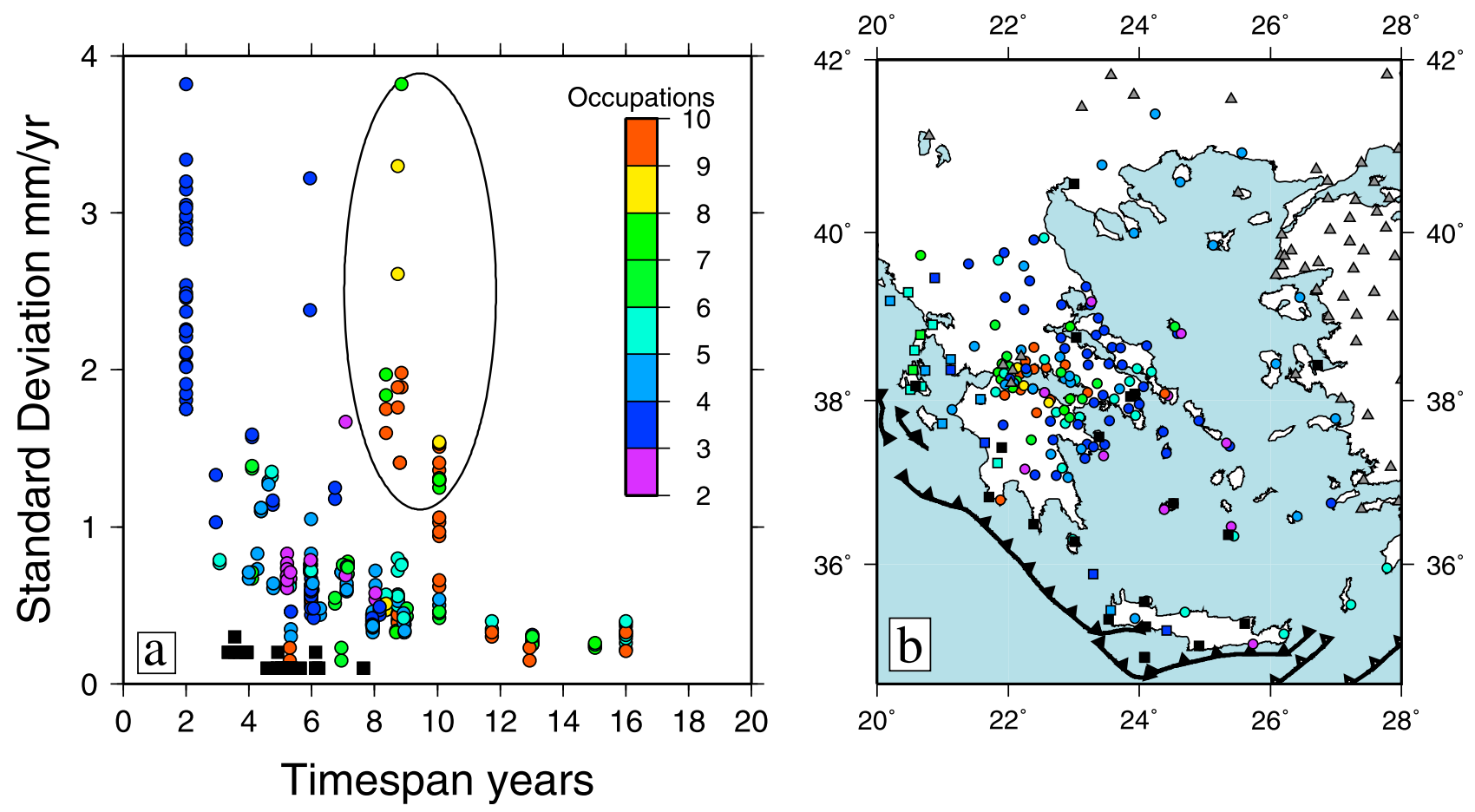

Figure 2. (a) The standard deviations of velocity components for the sites whose velocities were determined in this study, plotted against the time span of occupation (time elapsed between first and last occupation of the site). Circles represent survey-mode sites, with the number of occupations indicated by the shading; black squares represent continuous GPS (CGPS) sites. Sites within the ellipse were within $30 \mathrm{~km}$ of the 1995, Aigion, earthquake. The distribution of standard deviations for the velocities determined by Reilinger et al. [2006] is similar to that shown here. The standard deviations reported by Hollenstein et al. [2008] for their survey-mode GPS sites lie in the range $1-2 \mathrm{~mm} \mathrm{yr}^{-1}$, varying little with the duration of occupation, which is in the range 5-9 years; the standard deviations for their CGPS sites are all lower than $0.5 \mathrm{~mm} \mathrm{yr}^{-1}$. (b) All GPS sites used in this paper, with shading as in Figure 2a; sites whose velocities were determined in this study are shown by black squares (CGPS) or shaded circles (survey-mode), sites of Reilinger et al. [2006] used here are shown by triangles, and those of Hollenstein et al. [2008] are shown by shaded squares (CGPS sites as open squares).

quakes, and no survey-mode site was close enough to the $M_{w} 6.0,7$ September 1999, Athens earthquake or the $M_{\mathrm{w}} 6.7$, 8 August 2006, Kythira earthquake to experience measurable displacement. Sites within $30 \mathrm{~km}$ of the epicenter of the $M_{w} 6.6,13$ May 1995, Kozani-Grevena earthquake were occupied only after the earthquake and, because postseismic motions exceed the probable long-term velocities of those points with respect to Europe, those sites are not used in this study. Sixteen survey-mode sites within $30 \mathrm{~km}$ of the epicenter of the $M_{w} 6.2,15$ June 1995, Aigion earthquake showed a clear offset at the time of the earthquake and, for those with more than three occupations after the earthquake, transient motion was detectable for up to 3 years after the earthquake. For each site within $30 \mathrm{~km}$ of the epicenter, we excluded data for 3 years after the earthquake, and solved for the velocity plus an offset at 1995.45; this offset represents the displacement from immediately before the earthquake until mid-1998. For the single site that showed measurable displacement as a result of the M5.9, 18 November 1992, Galaxidi earthquake, we solved for a velocity plus offset, but no data were excluded. Several CGPS sites in Peloponnese showed pronounced coseismic and postseismic displacements after the $M_{w} 6.9$, Methoni earthquake of 14 February
2008. For that reason we do not include those data in the final solution.

[15] Our final solution is expressed in the ITRF2005 [Altamimi et al., 2007], using a 14-parameter transformation that minimizes the departure of the positions and velocities at the 363 IGS sites included in our processing from their ITRF2005 values. Using this approach, we find typical standard deviation of $\sim 0.25 \mathrm{~mm} \mathrm{yr}^{-1}$ and $\sim 0.9 \mathrm{~mm} \mathrm{yr}^{-1}$ on horizontal and vertical components of velocity for the continuous sites benefiting from 3 years of data and $\sim 0.15 \mathrm{~mm}$ $\mathrm{yr}^{-1}$ and $\sim 0.5 \mathrm{~mm} \mathrm{yr}^{-1}$ for the sites with 5 or more years of data. We do not estimate vertical velocities for the surveymode sites, and standard deviations in their horizontal components of velocity are mostly in the range $0.5-2 \mathrm{~mm}$ $\mathrm{yr}^{-1}$ (Figure 2). Two groups of sites have standard deviations in the range $2-4 \mathrm{~mm} \mathrm{yr}^{-1}$. For sites near the Aigion earthquake, the coseismic and postseismic offsets that we estimated were tens to hundreds of millimeters in magnitude and the associated uncertainties are larger than for those of otherwise comparable sites. In addition, about twenty sites that were occupied three times over an interval of 2 years show standard deviations of velocity components in the range $2-4 \mathrm{~mm} \mathrm{yr}^{-1}$. 
[16] To complete our velocity field, we combined our velocities with those of two other studies. Reilinger et al. [2006] reported velocities of sites over a large area of Arabia and southern Eurasia, of which the sites in Greece form part of the network reported here. We also include from that study sites within Turkey and west of $29^{\circ} \mathrm{E}$, which allow us to connect the deformation in the islands of the eastern Aegean to that of the major graben in western Turkey. Hollenstein et al. [2008] reported velocities of sites that mainly lie close to the Hellenic Trench (Figure 1), with some in central Greece that are coincident with sites in our network.

[17] For each of those studies, we identified sites that are coincident with, or lie within $1 \mathrm{~km}$ of, sites of our network within the Aegean, then found the angular velocity that minimizes the differences between the two different estimates of velocities of those sites. The RMS difference in velocity for the 30 sites common to our study and that of Reilinger et al. [2006] was $0.9 \mathrm{~mm} \mathrm{yr}^{-1}$, and the RMS misfit of these differences to the angular velocity was $0.5 \mathrm{~mm} \mathrm{yr}^{-1}$; the equivalent figures for the data of Hollenstein et al. [2008] were $2.7 \mathrm{~mm} \mathrm{yr}^{-1}$ and $1.8 \mathrm{~mm} \mathrm{yr}^{-1}$. In each case, we retained our solution for the velocity of the common sites.

[18] Finally, we checked for outliers among the velocities by estimating a locally linear velocity field that best fit, in the least squares sense, the velocities of all the points within $40 \mathrm{~km}$ of each site. We did not make such an estimate if there were fewer than 5 points within $40 \mathrm{~km}$ of the site so, in general, sites on the islands in the Aegean Sea could not be checked. For four sites out of 258 , the velocity calculated in this way differed from the observed velocity by more than $7 \mathrm{~mm} \mathrm{yr}^{-1}$, and those sites were excluded. Our final velocity field contains 254 sites, 156 from the present study, 62 additional sites from that of Reilinger et al. [2006], and 37 from Hollenstein et al. [2008] (auxiliary material).

\section{Results}

[19] The sites in our network exhibit the generally southwestward motion of the Aegean region with respect to Eurasia that has been observed in all previous studies. The geographic cardinal directions have no significance in this context, however, so we show the velocities in an oblique Mercator projection about a pole that is obtained by finding the angular velocity that best describes the velocities of those points within our network that move relative to Eurasia at more than $2 \mathrm{~mm} \mathrm{yr}^{-1}$. Viewed in that projection (whose lines of oblique latitude are perpendicular to the west Hellenic Trench, Figure 3), the velocities show a simple pattern with a predominant orientation toward the western Hellenic Trench, confirming the primary role that this boundary plays in the tectonics of the region [e.g., McKenzie, 1972; Le Pichon, 1982]. In the northwestern part of the region (above the line A in Figure 3) the velocities drop off from about $35 \mathrm{~mm} \mathrm{yr}^{-1}$ at the Hellenic Trench to $\sim 5 \mathrm{~mm} \mathrm{yr}^{-1}$ over about $400 \mathrm{~km}$ from the Trench (profile A in Figure 4). In the southeastern part of the region, below line $\mathrm{B}$, velocities at the trench are about $35 \mathrm{~mm} \mathrm{yr}^{-1}$

\footnotetext{
${ }^{1}$ Auxiliary materials are available at $\mathrm{ftp} / / / \mathrm{ftp}$.agu.org/apend/jb/ 2009jb007040.
}

and there is a smooth transition, also over about $400 \mathrm{~km}$, to the approximately westward movement of western Turkey at $20 \mathrm{~mm} \mathrm{yr}^{-1}$ (profile B in Figure 4). To the northwest of the lines $\mathrm{A}$ and $\mathrm{B}$ there is also a pronounced gradient of velocity in the NW direction (profiles C and D in Figure 4).

[20] In some respects, particularly in the smooth gradients of velocity on profiles B, C, and D of Figure 4, this distribution of velocities resembles what would be expected from the deformation of a continuous medium. Other aspects of the velocities, however, give the impression that the lithosphere behaves in a discontinuous fashion. For example there is a sharp increase in velocity across the western Gulf of Corinth, which can be seen in profile A of Figure 4, and the roughly constant velocities from $400 \mathrm{~km}$ to $700 \mathrm{~km}$ in profiles $\mathrm{C}$ and D of Figure 4 suggest that the Cyclades and the southern Aegean may translate as a rigid block [e.g., Nyst and Thatcher, 2004; Reilinger et al., 2006]. We investigate both the degree to which these motions can be described by the relative rotation of blocks and the degree to which they can be fit by a smoothly varying strain rate field.

[21] In what follows, we use the term "block" to refer to a region of the crust whose motion is described entirely by a rotation about an axis passing through the center of the Earth; that is, the block is supposed to be rigid. It has become customary in the analysis of geodetic velocities to model the crust as a set of elastic blocks that move like rigid bodies except near their edges, where they distort in response to tractions applied by faults that are locked in the upper crust but slip continuously at depth [e.g., Savage and Burford, 1973; Meade and Hager, 2005]. We do not employ such calculations here because the additional complexity they introduce is unnecessary for our analysis, as we discuss in Section 3.1.

[22] The motivation for considering a smoothly varying strain rate field is that some theories of continental deformation postulate that the entire lithosphere of a deforming region responds to stresses applied at its edges and/or arising in its interior from contrasts in gravitational potential energy [e.g., Bird and Piper, 1980; England and McKenzie, 1982, 1983; Molnar and Lyon-Caen, 1988; Vilotte et al., 1982]. Such theories assign primary importance not to velocities but to stresses and hence to gradients of velocity.

\subsection{Block Models}

[23] Geodetic determinations of velocities in the Aegean region have been interpreted in terms of between two [Le Pichon et al., 1995] and six [Reilinger et al., 2006] blocks (Figure 5). Although Le Pichon et al. [1995] identified two large blocks in this region (northern Greece, and Anatolia), they concluded that much of the relative motion between these blocks was better regarded as being distributed through a broad plate boundary zone spanning the Aegean. Nyst and Thatcher [2004] and Reilinger et al. [2006], however, proposed solutions in which the entire region is covered by blocks (Figure 5).

[24] Nyst and Thatcher [2004] assumed four blocks (Figure 5a) and placed the block boundaries by trial and error in a way that reduced the misfit between observed GPS velocities and the predicted block motions. The resultant RMS misfits between their observed and model velocities are between 2.5 and $3.5 \mathrm{~mm} \mathrm{yr}^{-1}$ (Table 1); Nyst and Thatcher [2004] explained some of these misfits by the presence of 


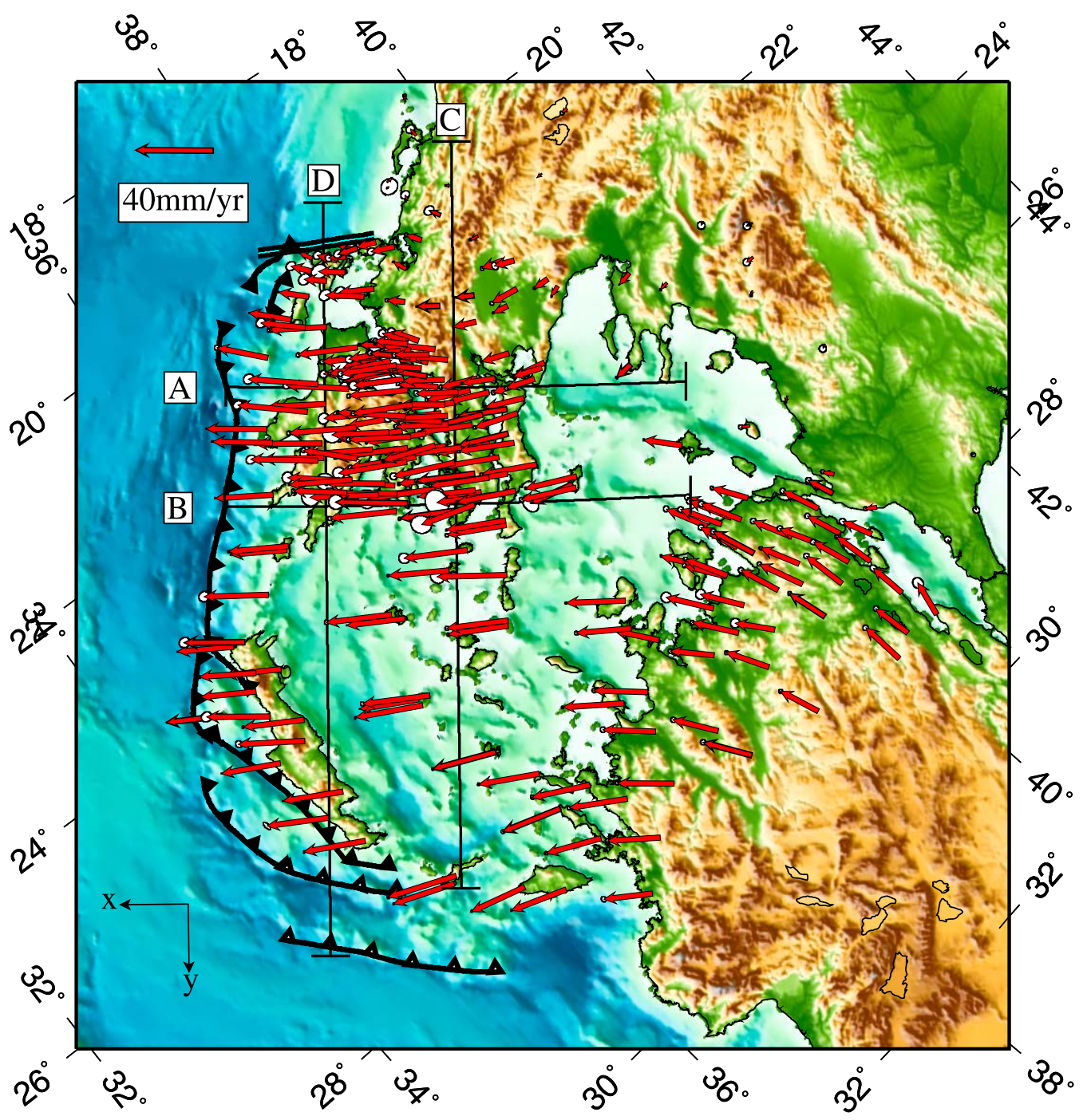

Figure 3. GPS velocities of this study, relative to stable Eurasia, in an oblique Mercator projection; lines of latitude about this pole run across the page. We refer in the text to the oblique latitudinal and longitudinal directions as $x$ and $y$ directions, respectively; these are shown by arrows in the bottom left. Lines A, B, C, D, show the locations of profiles used in Figure 4.

rapidly deforming zones embedded within the blocks and, by excluding approximately $20 \%$ of the observations, could reduce their RMS misfits to lower than $2 \mathrm{~mm} \mathrm{yr}^{-1}$.

[25] Using the same arrangement of blocks as Nyst and Thatcher [2004], we solve for the angular velocities that best fit, in the least squares sense, the velocities we have obtained for the sites on each block. (Note that we restrict our analysis to sites within our network so that although some blocks of Nyst and Thatcher [2004] extend further eastward than $29^{\circ} \mathrm{E}$, we use no data east of that longitude in our fit.) To avoid overemphasis of the CGPS sites, which cluster close to the Hellenic Trench, we place a minimum uncertainty of $0.5 \mathrm{~mm} \mathrm{yr}^{-1}$ on each velocity component. Our results are insensitive to magnitude of this minimum uncertainty, in the range between 0.5 and $2 \mathrm{~mm} \mathrm{yr}^{-1}$, as would be expected from an examination of the distribution of uncertainties, shown in Figure 2.

[26] We find that in central Greece, Anatolia, and Marmara, misfits to the block model are at the same level (2-4 $\left.\mathrm{mm} \mathrm{yr}^{-1}\right)$ as found by Nyst and Thatcher [2004]. However, our velocity field is significantly denser than that of Nyst and Thatcher [2004] in the Peloponnese and the southern Aegean (their South Aegean block), and here velocities are inconsistent with rigid body rotation, with an RMS misfit per component of $4.6 \mathrm{~mm} \mathrm{yr}^{-1}$ (Table 1). These misfits exceed, by a factor of $\sim 2$ (Figure 2), the uncertainties in the velocities and are, furthermore, systematic, reflecting arc-parallel extension from the Cyclades to Crete, and north-south dextral shear in western Greece (see also Davies et al. [1997], Hollenstein et al. [2008], and Figure 15).

[27] This level of misfit suggests that if the description of Aegean tectonics in terms of blocks is to be preserved, a greater number of blocks is required. As part of a wider study of the entire collision zone between Africa, Arabia, and Eurasia, Reilinger et al. [2006] divided the Aegean region into six blocks, basing the choice of block boundaries on the observed major faults of the region (Figure 5b). As with the block model of Nyst and Thatcher [2004], the 

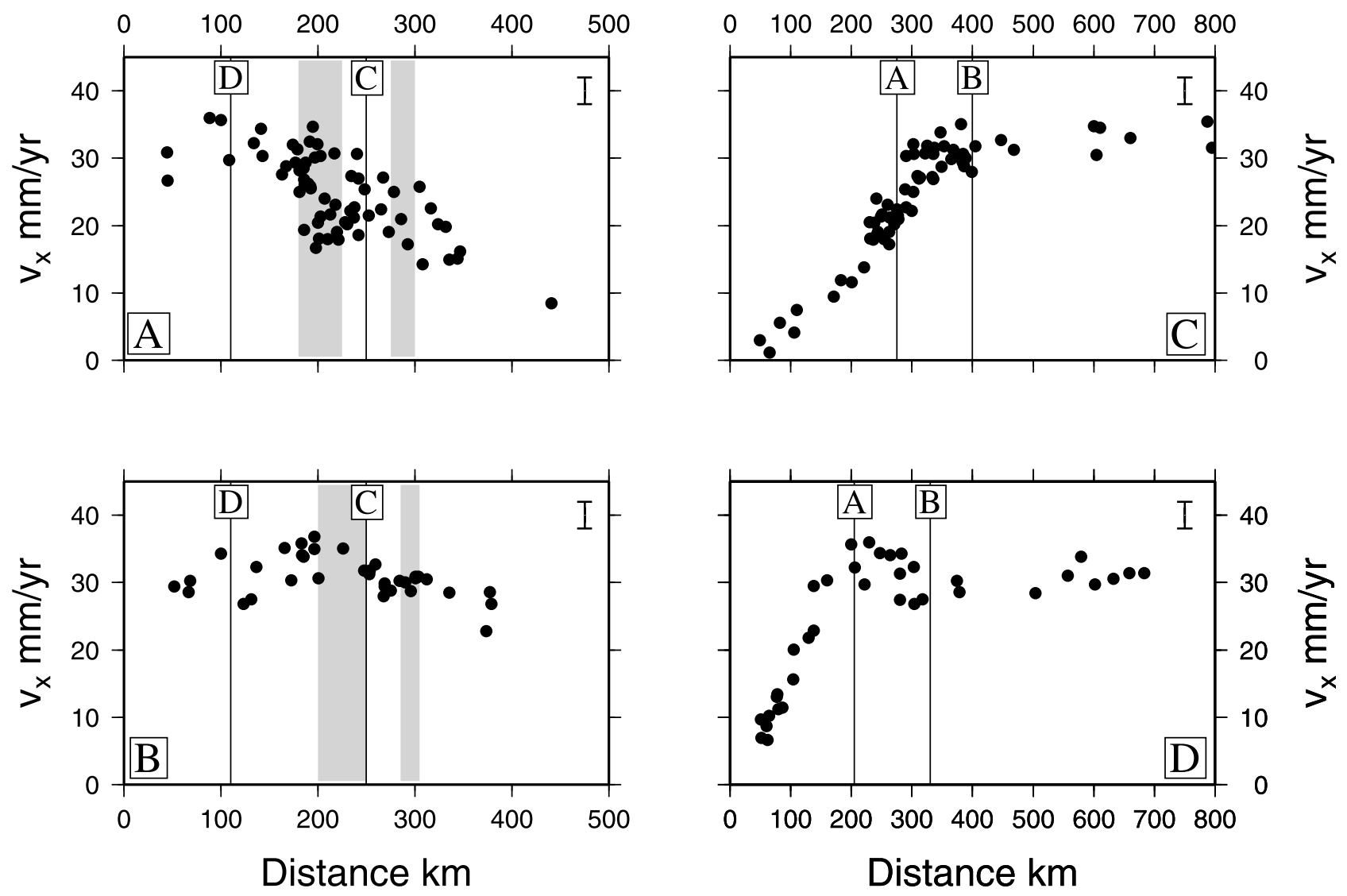

Figure 4. Cross sections of $v_{x}$ along lines whose locations are shown in Figure 3; $v_{x}$ is the component of velocity parallel to oblique lines of latitude for the pole used in the oblique Mercator projection of Figure 3; error bars at top right of each panel indicate representative uncertainties in the velocity. In each case, all sites within $50 \mathrm{~km}$ of the track are used. Shaded bands in profiles A and B represent the locations of the Gulfs of Corinth and Evvia (profile A) and the Gulfs of Saros and Evvia (profile B) (see Figure 1). Vertical lines with labels show the locations, on each profile, where they are crossed by other profiles. Velocities lower than $\sim 20 \mathrm{~mm} \mathrm{yr}^{-1}$ near $200 \mathrm{~km}$ on profile A are from NW Greece, where $v_{x}$ drops off rapidly in the direction perpendicular to the profile (Figure 3 ).

misfits between our observations and the block model are at the level of 2-3 $\mathrm{mm} \mathrm{yr}^{-1}$, except in the southern Aegean and Peloponnese, where the RMS misfit is $4.9 \mathrm{~mm} \mathrm{yr}^{-1}$ (Table 1 and Figure $6 \mathrm{~b}$ ). We do not attempt to improve the fit by calculating elastic deformation from slipping dislocations at depth beneath the block boundaries; such deformation is restricted to a few tens of kilometers from the boundary, and it is clear that the misfits in the southern Aegean are distributed across the whole region.

[28] To investigate the influence of using a finer scale of block, we adopt the suggestion of Taymaz et al. [1991] that the northern and central Aegean may be treated as a set of parallel slats that are aligned with the major fault systems of the region. In western Turkey, central Greece and the Peloponnese, we align the slats with the major normal-fault systems, while in the northern Aegean, we align them with the system of right-lateral strike-slip faults that are the westward continuation of the North Anatolian fault (Figure 7a; see also Goldsworthy et al. [2002, Figure 18]). We treat the large velocity gradients across the southern Aegean by placing two block boundaries running approximately north-south through the Peloponnese, parallel to the major normal faults of the region, and a third running south through the central Cyclades and Crete. In this configuration there are 10 blocks, each 100 $200 \mathrm{~km}$ in width (Figure 7a). We also investigate a modification to this model that is suggested by the observation [Goldsworthy et al., 2002] of continuous systems of active faulting that cross central Greece. We place additional block boundaries (1) joining the eastern end of the Gulf of Corinth to southern Evvia, corresponding to the approximate location of the Thiva-Evvia fault system [Goldsworthy et al., 2002, section 3.1], (2) joining the western Gulf of Corinth to the Kefalonia strike-slip fault [Goldsworthy et al., 2002, section 4.1], (3) through Thessaly [Goldsworthy et al., 2002, section 3.3] and (4) between the western Gulf of Corinth and Thessaly. In this configuration there are 15 blocks. For each of these models, the RMS misfit of velocities within individual blocks is $2-3 \mathrm{~mm} \mathrm{yr}^{-1}$; for the 10 -block model, the overall RMS misfit is $2.8 \mathrm{~mm} \mathrm{yr}^{-1}$ (Figure $8 \mathrm{a}$ ), while for the 15-block model it is $2.6 \mathrm{~mm} \mathrm{yr}^{-1}$ (Figure $8 \mathrm{~b}$ ).

[29] We investigated several other configurations of between 10 and 20 blocks, for example, one that retains the block configuration of Reilinger et al. [2006] but divides their southern Aegean block into four and one that divides the region into 20 polygons of approximately equal dimensions. We found that each configuration fit the observed 

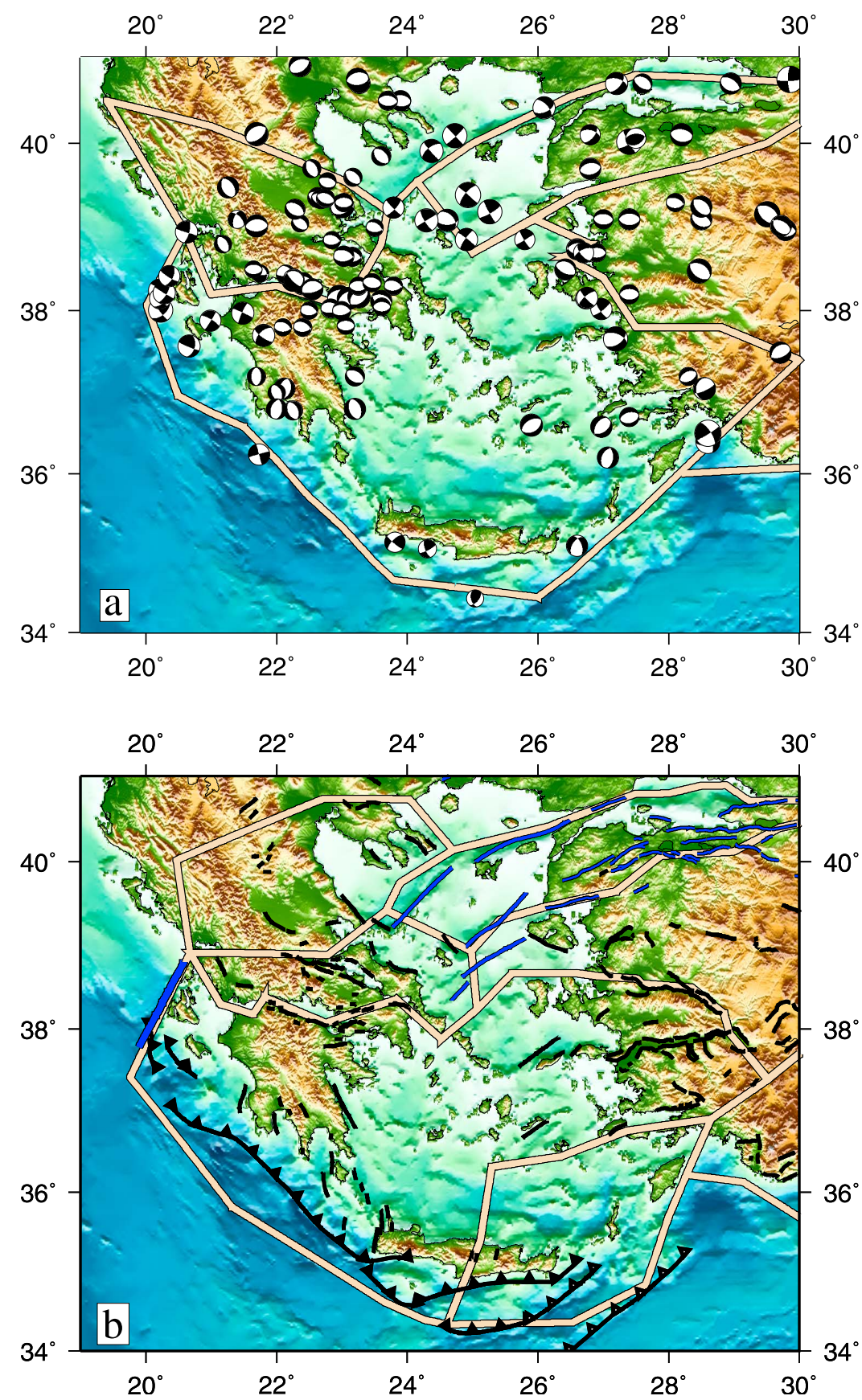

Figure 5. Block models of the Aegean region proposed by (a) Nyst and Thatcher [2004] and (b) Reilinger et al. [2006]. Block boundaries are shown by tan lines. Focal mechanism representations in Figure 5a are for earthquakes of $M_{b} \geq 5.8$ that occurred within the region since 1890 [Ambraseys and Jackson, 1990; Jackson and McKenzie, 1988; Shaw and Jackson, 2010]. Only focal mechanisms of earthquakes within the Aegean continental lithosphere are shown; reverse faulting at, and outboard of, the trenches is not shown. Faults in Figure 5b: toothed lines are reverse faults of the Hellenic Ptolemy, Pliny, and Strabo trenches; blue lines represent strike-slip faults, all of which have a right-lateral sense of slip; black lines represent normal faults (J. Jackson and E. Nissen, personal communications, 2010).

velocities to within $2-3 \mathrm{~mm} \mathrm{yr}^{-1} \mathrm{RMS}$, provided that the blocks were no larger than those illustrated in Figure 7. It is probable that misfits could have been reduced if the block boundaries had been modeled by faults slipping continuously at depth below an elastic lid [e.g., Meade et al., 2002; Reilinger et al., 2006]. However, the influence of the elastic lid is to distribute the slip at depth over a horizontal distance that is about $\pi$ times the thickness of the lid. With a likely thickness of $15 \mathrm{~km}$ for that lid (estimated from long-period body wave modeling of the depth of nucleation of large earthquakes in the region, from aftershock studies, and from interferometric synthetic aperture radar [Baker et al., 1997; 
Table 1. Parameters of Kinematic Fits to the Velocities Reported in This Study ${ }^{\mathrm{a}}$

\begin{tabular}{lccc}
\hline & $\begin{array}{c}\text { Number of } \\
\text { Parameters }\end{array}$ & $\begin{array}{c}\text { Original } \\
\text { Study RMS } \\
\left(\mathrm{mm} \mathrm{yr}^{-1}\right)\end{array}$ & $\begin{array}{c}\text { This Study } \\
\text { RMS } \\
\left(\mathrm{mm} \mathrm{yr}^{-1}\right)\end{array}$ \\
\hline 4 blocks (Figure 6a) $^{\mathrm{b}}$ & $\geq 12$ & $2.8(2.6)^{\mathrm{c}}$ & 3.9 \\
Central Greece (CG) & 3 & $2.9(2.3)^{\mathrm{c}}$ & 3.1 \\
South Aegean (SA) & 3 & $3.4(3.7)^{\mathrm{c}}$ & 4.6 \\
Anatolia (AN) & 3 & $2.7(2.1)^{\mathrm{c}}$ & 2.2 \\
Marmara (MA) & $\geq 3$ & $2.4(4.3)^{\mathrm{c}}$ & 2.6 \\
& $\geq 18$ & $2.8(2.4)^{\mathrm{e}}$ & 3.9 \\
6 blocks (Figure 6b) & $\geq 3$ & $3.1(2.4)^{\mathrm{e}}$ & 4.9 \\
Aegean (AG) & $\geq 3$ & $2.8(2.6)^{\mathrm{e}}$ & 2.2 \\
Anatolia (AN) & $\geq 3$ & $1.3(1.0)^{\mathrm{e}}$ & 2.7 \\
Central Greece (CG) & $\geq 3$ & $2.9(2.5)^{\mathrm{e}}$ & 2.6 \\
Marmara (MA) & $\geq 3$ & $2.9(2.1)^{\mathrm{e}}$ & 2.3 \\
Northern Greece (NG) & $\geq 3$ & $2.1(1.8)^{\mathrm{e}}$ & 2.2 \\
SE Aegean (SE) & 30 & - & 2.8 \\
$\quad$ 10 blocks (Figure 8a) & 45 & - & 2.6 \\
15 blocks (Figure 8b) & & & \\
$\quad$ Continuous $(\alpha=400 \mathrm{~km}$, & & - & 3.3 \\
$\quad$ not illustrated) & & & \\
Continuous $(\alpha=120 \mathrm{~km}$, & & & \\
$\quad$ Figure 11) & & & \\
\hline
\end{tabular}

${ }^{\mathrm{a}}$ The 4-block model of Nyst and Thatcher [2004] (Figure 6a); 6-block model of Reilinger et al. [2006] (Figure 6b), and 10- and 15-block models (Figures 7 and 8); continuous models (Figure 11). The number of parameters for each model is expressed as a lower bound in the case of block models that require additional parameters to represent deformation due to buried slip at block boundaries; the misfits to the models are given; all RMS misfits referred to in this paper are misfits per component of velocity. Also given are the misfits between the velocities reported here and the various models; all blocks are treated as rigid, and no deformation due to buried slip is calculated.

${ }^{\mathrm{b}}$ Nyst and Thatcher [2004].

${ }^{\mathrm{c}}$ The RMS misfit between the velocities of Nyst and Thatcher [2004] and the predictions of their block model; numbers in parentheses are the WRMS misfits given by Nyst and Thatcher [2004], who allow for elastic deformation due to buried slip on the North Anatolian fault.

${ }^{\mathrm{d}}$ Reilinger et al. [2006].

${ }^{\mathrm{e}}$ The RMS misfit between the velocities of Reilinger et al. [2006] and the predictions of their block model; numbers in parentheses are the WRMS misfits given by Reilinger et al. [2006], who also estimate deformation due to buried slip at their block boundaries.

Bernard et al., 1997; Hatzfeld et al., 1995, 1997b, 2000; Jackson et al., 1982; Meyer et al., 1996; Resor et al., 2007; Taymaz et al., 1991; Shaw and Jackson, 2010]), the deformation associated with the block boundaries would be spread over $\sim 50 \mathrm{~km}$, and with the slats in Figure 7 being $\sim 50-100 \mathrm{~km}$ wide, there would be little difference between a description in terms of blocks and one in terms of distributed deformation. We therefore regard as unnecessary the introduction of the additional parameters required for elastic block modeling (thickness of elastic lid, dips of each fault segment).

\subsection{Continuous Model}

[30] Early large-scale measurements of strain in Greece from reoccupations of a late 19th century triangulation [Billiris et al., 1991; Veis et al., 1992; Davies et al., 1997] suggested that at the spatial resolution of the 19th century network $(60-100 \mathrm{~km})$, most parts of the region exhibit resolvable displacement gradients over 100 years, though the strains vary laterally by at least a factor of 10 . Davies et al. [1997] found that all the 100-year displacements which Billiris et al. [1991] and Veis et al. [1992] measured could be fit by polynomials of degree 2 with misfits of less than $0.4 \mathrm{~m}$ (equivalent to $4 \mathrm{~mm} \mathrm{yr}^{-1}$ ).

[31] In order to form a measure of continuous deformation, we employ the method of Shen et al. [1996] to calculate a smoothly varying field of velocity gradient. At each location, we assume uniform gradients in the components of horizontal velocity and estimate these gradients, along with the velocity of the location, by least squares inversion; all sites are included in the inversion, but each is allotted, according to its distance from the location, a Gaussian weighting of full width $\alpha$. In order to avoid overweighting of points close to the location of interest in places where coverage is sparse (mostly within the Aegean islands), we set a minimum weight for all points that is equal to one over the total number of points. We use this procedure to calculate both the misfit of the velocities of individual sites to a locally smooth field (Figures 9 and 10), and to form estimates of the velocity gradients on regular grids (Figure 11).

[32] For a network of homogeneously distributed sites, the Gaussian weighting would assign $63 \%$ of the weight to sites lying within a circle of diameter $\alpha$ of the point in question, so in what follows, we use $\alpha$ as a measure of the spatial resolution of the continuous models. Figure 9 shows the dependence upon $\alpha$ of the RMS misfit of the observed velocities to such a smooth field. With $\alpha=400 \mathrm{~km}$ (approximately the spatial resolution of the degree two polynomials used by Davies et al. [1997]), the RMS misfit is $\sim 3 \mathrm{~mm} \mathrm{yr}^{-1}$, slightly smaller than was obtained by Davies et al. [1997] from reoccupations of the 19th century triangulation points.

[33] Estimation of the velocity gradient involves six quantities (the velocity of the point of interest plus two spatial derivatives of each component of horizontal velocity), and a reasonable measure of the spatial resolution offered by the distribution of GPS sites is the diameter, $\alpha_{6}$, of a circle that must be drawn around each site in order that it should contain at least six points (the point itself plus its five nearest neighbors). The upper panel in Figure 9 shows that fewer than $25 \%$ of sites have $\alpha_{6}<50 \mathrm{~km}$, whereas $\sim 75 \%$ of sites have $\alpha_{6}<120 \mathrm{~km}$. We therefore now present and discuss a continuous representation of the velocity gradients calculated with $\alpha=120 \mathrm{~km}$ (Figure 11).

[34] Regions of Greece and western Turkey between approximately $37.5^{\circ} \mathrm{N}$ and $40^{\circ} \mathrm{N}$ are characterized by predominantly north-south extension, and a band of trenchnormal compression and trench-parallel extension follows the Hellenic trench. The trench-parallel compression has been discussed by a number of authors [Shaw et al., 2008; Ganas and Parsons, 2009; Reilinger et al., 2010] but is outside the scope of this paper. In the northeastern part of the region, the field of velocity gradients shows a zone of right-lateral shear on nearly east-west planes corresponding to the western end of the North Anatolian fault system and the North Aegean Trough, and a second zone of right-lateral shear in western Greece. We note that the absence of contractional principal axes in the strain rate field of central Greece (Figure 11) shows that right-lateral shear is not continuous between the North Aegean Trough and the western coast of Greece. The explanation for this can most readily be understood by referring to the velocities shown in Figure 3, in which the $x$ direction is oriented approximately 

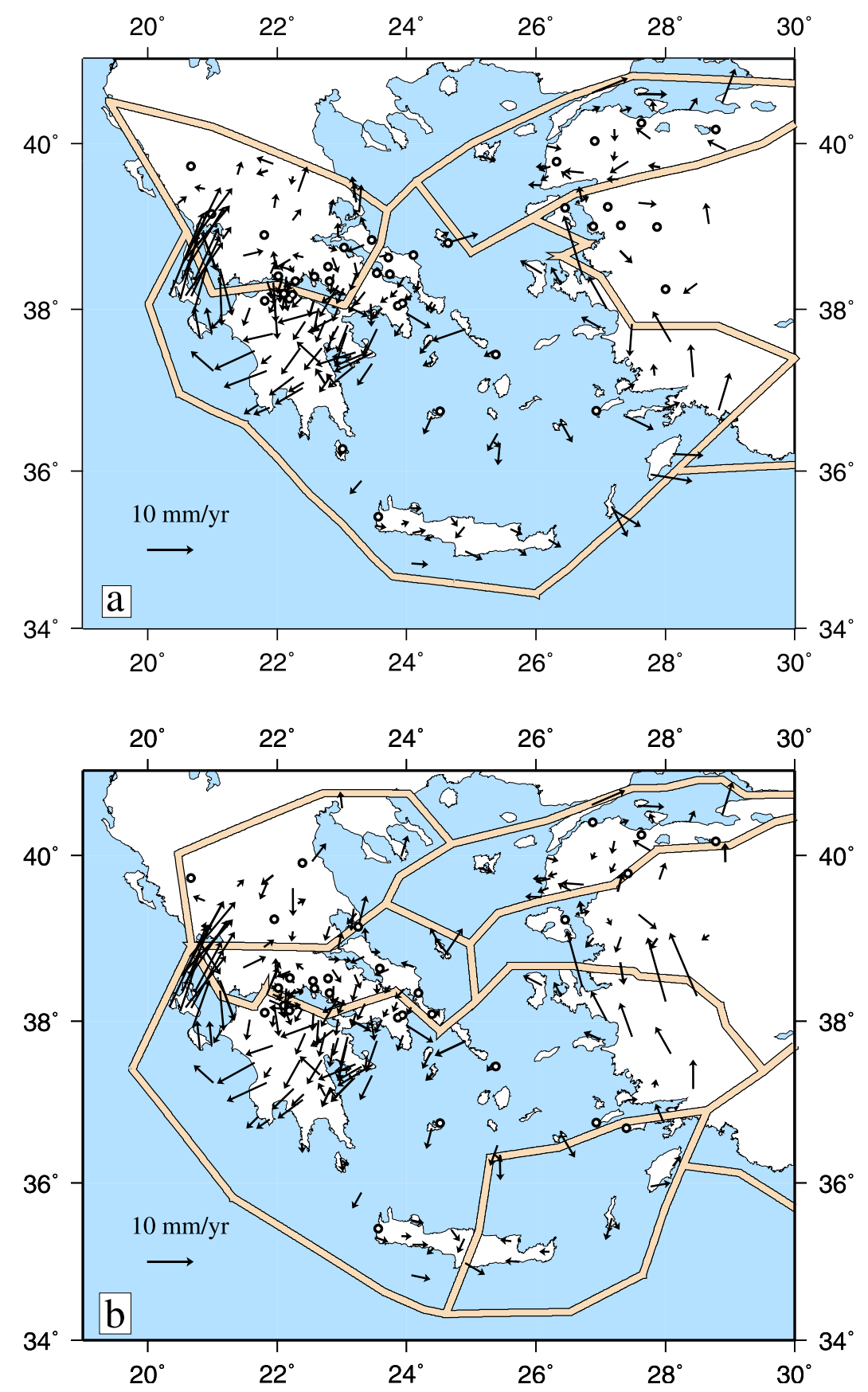

Figure 6. Misfits between the velocities reported here and best fitting angular velocities for the block models of Figure 5. Arrows for sites whose misfits are lower than $1.5 \mathrm{~mm} \mathrm{yr}^{-1}$ are too small to be shown clearly; these sites are represented by open circles. (a) Misfits to the best fitting angular velocities for the blocks of Nyst and Thatcher [2004]. (b) Misfits to the best fitting angular velocities for the blocks of Reilinger et al. [2006].

SW. A NW gradient of SW directed velocity $\left(\partial v_{x} / \partial y\right)$ is always present across the region, but variations in the relative magnitudes of this gradient and the NE gradient of SE directed velocity $\left(\partial v_{y} / \partial x\right)$ determine whether those gradients are expressed in shear, rotation, or both. In the northeastern Aegean, the gradients of velocity $\partial v_{x} / \partial y$ and $\partial v_{y} / \partial x$ are approximately equal and opposite in magnitude, and the deformation takes place by shear with little rotation. In central Greece these velocity gradients are approximately equal and the deformation takes place by normal faulting and rotation [McKenzie and Jackson, 1983]. In western Greece, the NW gradient of SW directed velocity $\left(\partial v_{x} / \partial y\right)$ dominates, and the deformation takes place by a combination of shear and rotation (Figure 11).

[35] The RMS misfit of the observed velocities to this smooth field is $2.3 \mathrm{~mm} \mathrm{yr}^{-1}$. Systematic misfits are confined to a region approximately 100 -by- $100 \mathrm{~km}$ around the Gulf of Corinth, where they reach about $5 \mathrm{~mm} \mathrm{yr}^{-1}$ (Figure 10); this observation is consistent with previous studies, which have shown that approximately $12 \mathrm{~mm} \mathrm{yr}^{-1}$ of extension are 

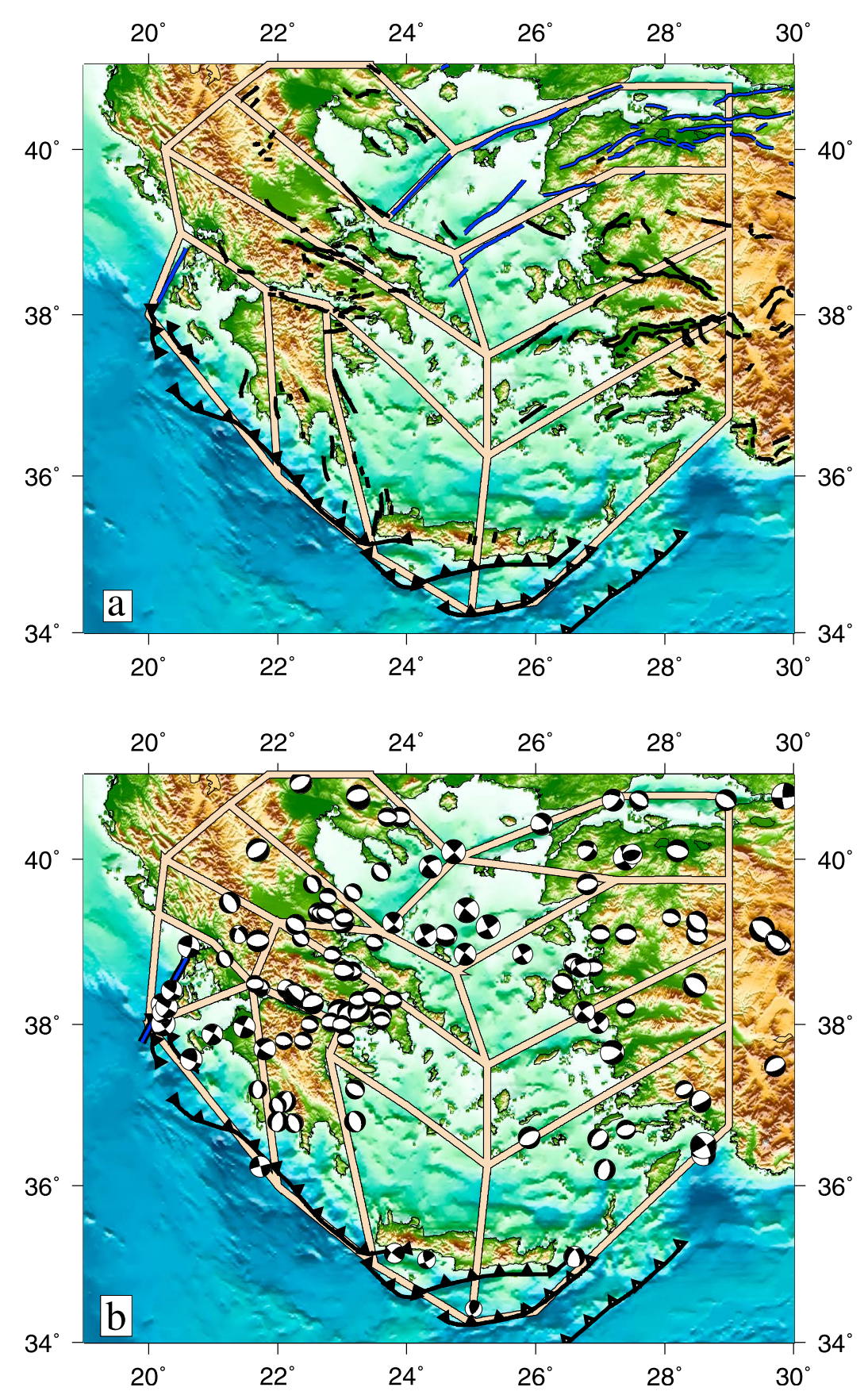

Figure 7. (a) Distribution of blocks in the Aegean based on the "broken-slat" model proposed by Taymaz et al. [1991]. (b) Modification to Figure 7a with additional block boundaries in central and western Greece, as discussed in the text. Block boundaries are shown by tan lines. Toothed lines are as in Figure 1; grey lines represent strike-slip faults, all of which have a right-lateral sense of slip; black lines represent normal faults (data from J. A. Jackson and E. Nissen (personal communications, 2010)). (b) Focal mechanisms are those of earthquakes $M_{b} \geq 5.8$ that have occurred in the region in the past 120 years [Ambraseys and Jackson, 1990; Jackson and McKenzie, 1988; Shaw and Jackson, 2010].

taken up in a few tens of kilometers across the western Gulf of Corinth [Clarke et al., 1997, 1998; Briole et al., 2000; Avallone et al., 2004]. Elsewhere, the misfits show no systematic pattern, and are generally smaller than $2 \mathrm{~mm} \mathrm{yr}^{-1}$ (Figure 12).

[36] The similar magnitudes of misfits for the two types of model demonstrate that it is equally valid to describe the observed geodetic velocities by uniform deformation on the scale of $\sim 100-120 \mathrm{~km}$ or to model it by the relative motion of blocks having the same scale. The RMS misfits are of order 2-3 $\mathrm{mm} \mathrm{yr}^{-1}$ both for the 10- and 15-block models (Figure 8), and for the $120 \mathrm{~km}$ resolution model (Figure 12). The block models that contain fewer, larger blocks provide, 

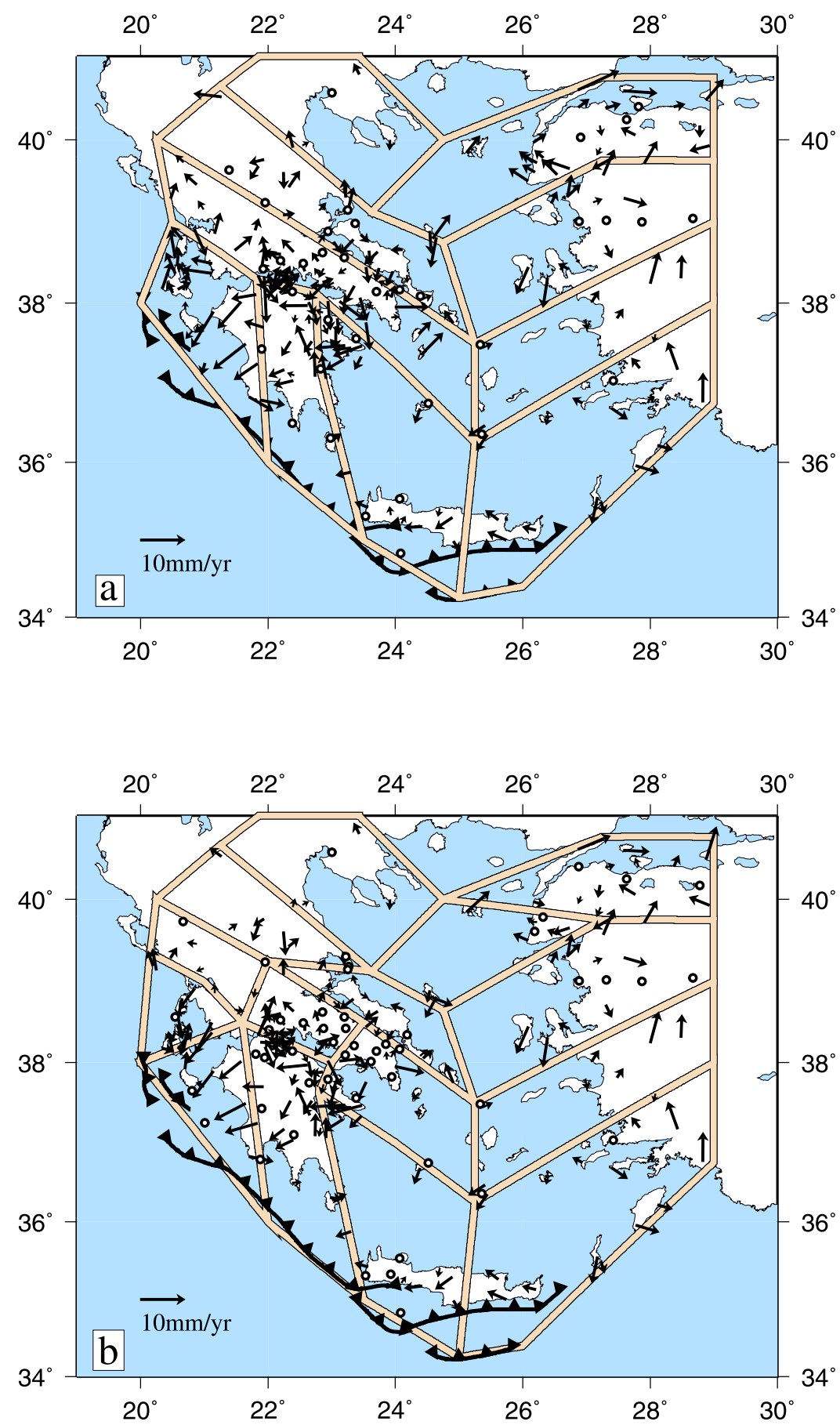

Figure 8. Misfits between the velocities reported here and best fitting angular velocities for the blocks of Figures $7 \mathrm{a}$ and $7 \mathrm{~b}$. Sites for which the misfit is lower than $1.5 \mathrm{~mm} \mathrm{yr}^{-1}$ are shown by open circles.

however, a poorer fit than do continuous representations having similar scale lengths (Table 1 and Figures 9 and 12).

\section{Discussion}

[37] The sites within our velocity field are subject to noise

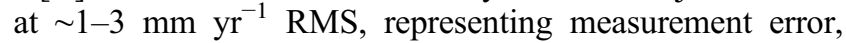
monument instability, local nontectonic movements and postseismic transient effects (Figure 2), so that the geodetic data alone do not allow us to distinguish between small block and continuous models. We therefore consider the implications for each model of other tectonic observations in the region.

[38] We emphasize that a continuous description of the deformation is not incompatible with block-like behavior of the upper crust. There can be no doubt that at some scale, the crust is split into fragments which are separated by faults and which, at any one time, may be treated as elastic blocks. The question is still open, however, as to whether the these 

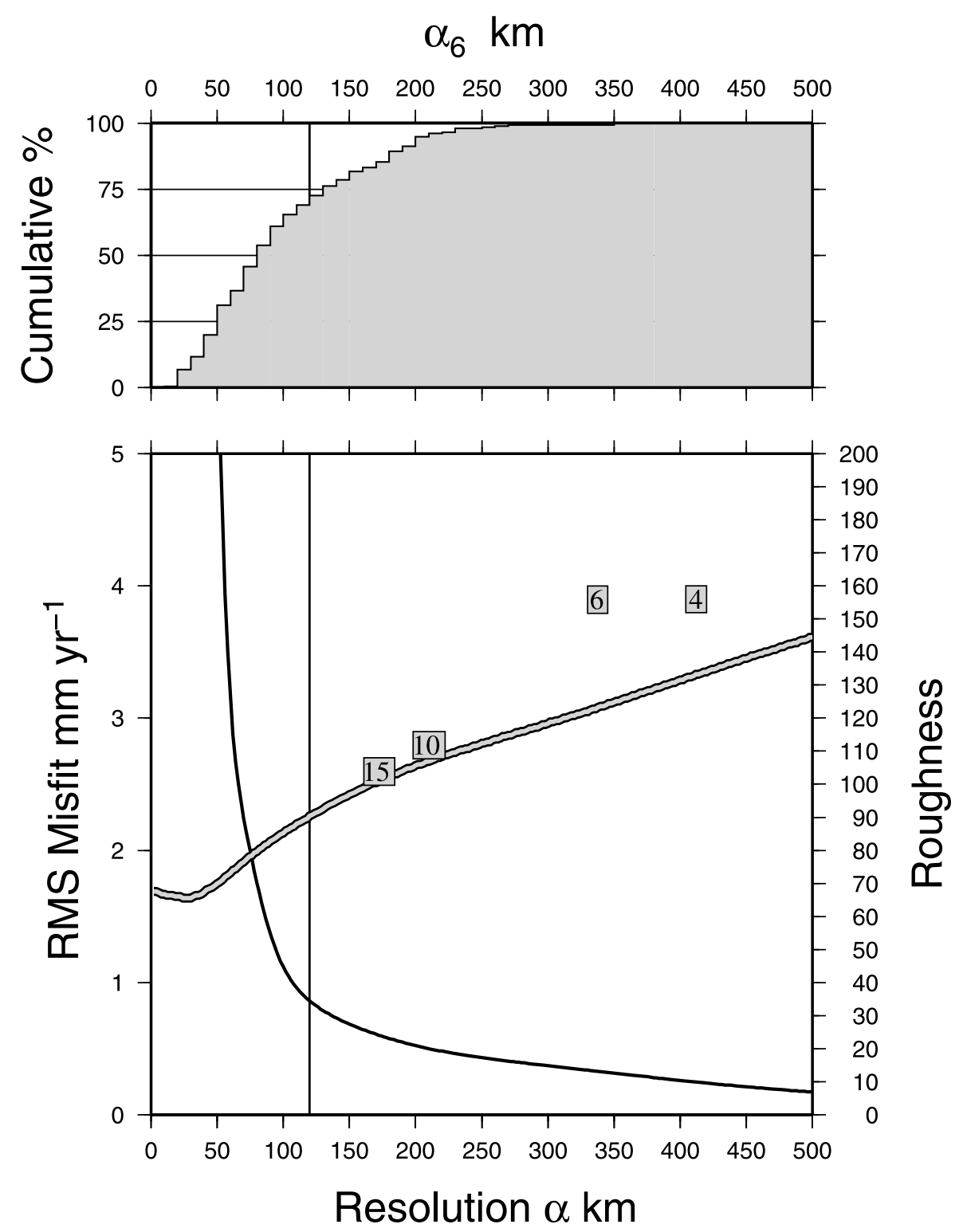

Figure 9. (bottom) Double line shows the RMS misfit of a continuous velocity field to the observed velocities as a function of the spatial resolution, $\alpha$, of the field. Single line shows the roughness (arbitrary units, right-hand axis) of the strain rate field, measured by the variance of the strain rate field, calculated on a $0.5 \times 0.5^{\circ}$ grid, from a plane. Numbers in boxes show the RMS misfits to models with those numbers of blocks (Figures 6 and 8 ) with horizontal coordinate given by the square root (in $\mathrm{km}$ ) of the average area of the blocks. (top) Distribution of spacing between sites; shaded region illustrates the cumulative percentage of sites having five neighbors within a distance $\alpha_{6}$. The velocity gradient field that we concentrate upon in this paper is calculated using $\alpha=120 \mathrm{~km}$ (Figure 11), marked by the vertical lines.

fragments move as a set of independent microplates, or whether they move (and may over time break up) in response to forces applied to them by the lower lithosphere [e.g., Bourne et al., 1998; England and Jackson, 1989; Molnar, 1988]. In the former case, it is appropriate to describe the motions by a set of angular velocities; in the latter, the apparatus of continuum mechanics may be more appropriate.

\subsection{Implications of Block Models for Aegean Tectonics and Seismic Hazard}

[39] We first compare the predictions of the block models with the observed distribution of deformation revealed by the earthquakes of the region during the past 120 years. The catalog of earthquakes having $M>5.8$ within the continental lithosphere of the Aegean is believed to be reasonably complete over the past 120 years [Ambraseys and Jackson, 1990; Jackson and McKenzie, 1988; Shaw and Jackson, 2010]. The moment release in $M>5.8$ earthquakes in the Aegean region since 1890 has been $\sim 10^{21} \mathrm{~N}$ m (Figure 14). Two arguments suggest that this moment release is comparable with the longer term rates within the Aegean. First, while $M>8$ earthquakes probably take place infrequently along the Hellenic trench [Ambraseys et al., 1994; Shaw et al., 2008], and earthquakes of magnitude close to 8 certainly 


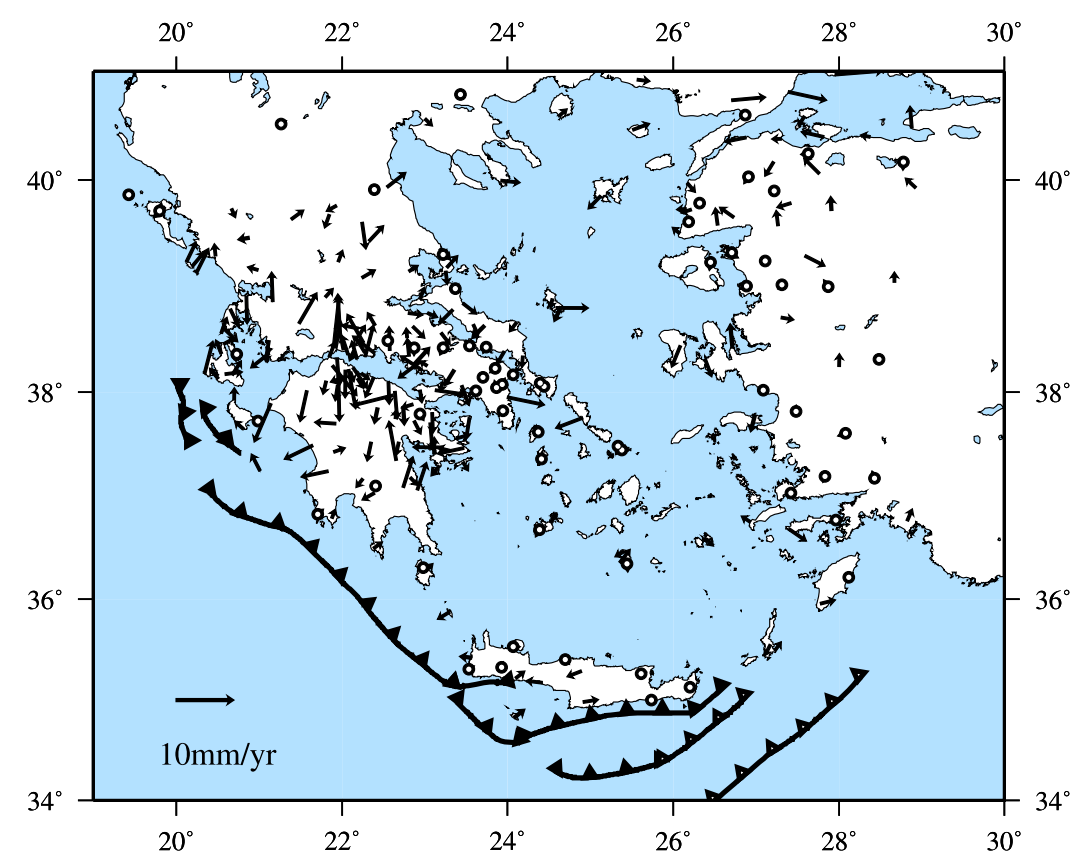

Figure 10. Misfits of observed velocities to the velocity gradient model illustrated in Figure 11. Sites for which the misfit is lower than $1.5 \mathrm{~mm} \mathrm{yr}^{-1}$ are shown by open circles.

occur along the North Anatolian fault [Barka, 1996], the maximum magnitudes of the normal faulting events in the region are likely to be limited by the length of the fault segments (10-20 km [Ambraseys and Jackson, 1990]). This argument may be extended to the strike-slip faults in the north Aegean and western Greece, where the segment lengths are consistent with the maximum magnitudes seen $(M \sim 7.5)$ seen in the past century. Secondly, this rate of moment release is consistent with the overall strain rate of the region being accommodated seismically [Jackson and McKenzie, 1988] (see section 3.2).

[40] For each model, we illustrate the relative motions between adjacent blocks by equivalent focal mechanisms (Figure 13). In general, the style of deformation predicted by the block models is consistent with what is seen in the earthquake record, with strike-slip deformation dominating in the northeast of the region, around the North Anatolian fault, and in western Greece, near the Kefalonia fault. There are, however, differences between the slip predicted by these models, and that observed in the earthquakes. The 4and 6-block models predict that some (or, in the case of the model of Nyst and Thatcher [2004], all) of the relative motion across central Greece is accommodated on strikeslip faults, which do not exist, while the 15-block model predicts a significant component of strike-slip deformation in western Turkey, which again does not exist, while failing to predict the strike-slip deformation in western Greece (see Figure 15). We do not rule out the possibility that reconfiguring the block boundaries could diminish these discrepancies, but because the locations of the block boundaries were chosen on the basis of the known distribution of faulting, it is not clear that any such reconfiguration would be consistent with the geology.
[41] One motivation for the use of block models is to attempt an economical description of the seismic hazard in a region. If all the major fault zones are identified and correctly assigned to block boundaries, then block models may provide useful constraints on slip rates, and hence on the accumulation of hazard [e.g., Reilinger et al., 2006]. If, however, a block model fails to capture the essentials of the active faulting, then its use in seismic hazard estimation may be seriously misleading: hazard will be overestimated near the boundaries of the blocks, and underestimated in their interiors.

[42] For example, Nyst and Thatcher [2004] conclude that the seismic hazard in the Aegean is concentrated near the boundaries of their four microplates (shown in Figure 5a) but $\sim 50 \%$ of the moment release in earthquakes during the past 120 years took place at distances greater than $30 \mathrm{~km}$ (twice the thickness of the seismogenic layer) from these block boundaries (Figure 14). As would be expected, the model containing 15 smaller blocks performs better, with only $20 \%$ of the moment release in earthquakes taking place more than $30 \mathrm{~km}$ from the block boundaries (Figure 14) but, at this scale of block, there are few parts of the region that do not lie within $30 \mathrm{~km}$ of a boundary.

[43] These considerations are clearly illustrated in western Greece, where a zone of distributed right-lateral shearing extends more than $200 \mathrm{~km}$ inland from the Kefalonia fault (profile D, Figure 4, and Figure 15). The Kefalonia fault, sometimes referred to as the Kefalonia Transform Fault [e.g., Louvari et al., 1999], is an obvious choice as a block boundary because there is a concentration of earthquakes along it and it is associated with a prominent offshore bathymetric scarp [Nyst and Thatcher, 2004; Reilinger et al., 2006; this paper, Figures 7 and 15]. Yet the gradient of velocity across this region (Figure 15b) cannot be interpreted 

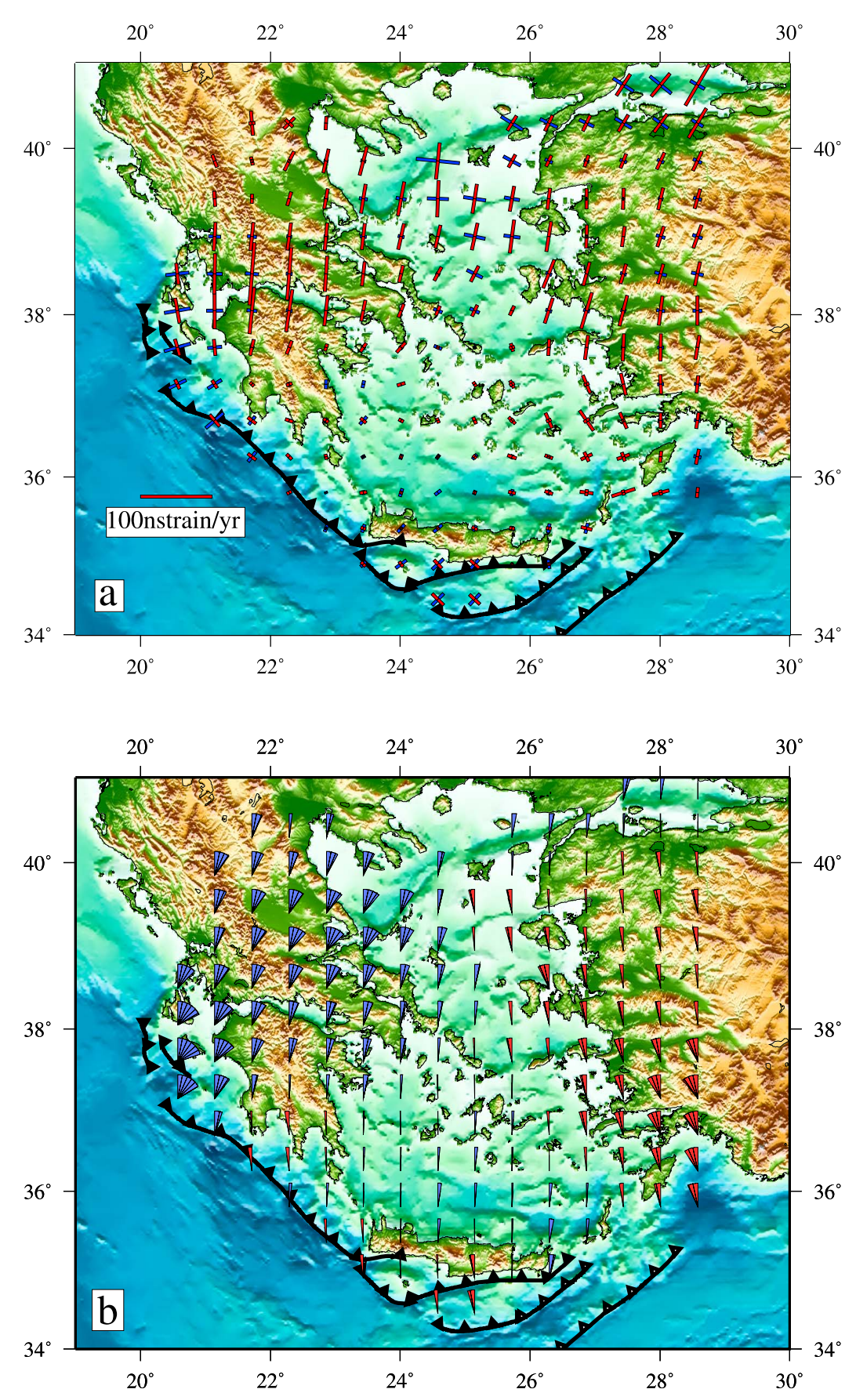

Figure 11. (a) Principal axes of strain rate estimated from the observed velocities by assuming locally homogeneous, but regionally varying, velocity gradients. Horizontal velocity, and local gradients of its components, are estimated, at each point on the grid, by least squares inversion giving each site a Gaussian weight of full width $120 \mathrm{~km}$ (Figure 9 and text). Extensional strain rates are shown as red bars, compressional strain rates as blue bars. (b) Rotation rates $\frac{1}{2}\left(\frac{\partial v_{x}}{\partial y}-\frac{\partial v_{y}}{\partial x}\right)$ of the velocity gradient field. Wedges represent the rotation rate multiplied by $10 \mathrm{Myr}$; blue wedges show clockwise rotation rates, counterclockwise rates are shown in red.

as the elastic response of a block to a fault that is slipping at depth beneath the Kefalonia fault; the length scale over which the velocity difference is expressed would require a locking depth of at least $80 \mathrm{~km}$ (i.e., the fault would penetrate through the downgoing Nubian plate) and, to fit the amplitude of the velocity difference, the slip rate on such a fault would need to exceed $70 \mathrm{~mm} \mathrm{yr}^{-1}$. A more reasonable interpretation of the velocity gradient, supported by the observations of shallow faulting of the region (Figure 15a) is that it represents distributed shearing across this part of western Greece, which is released by slip on a number of 

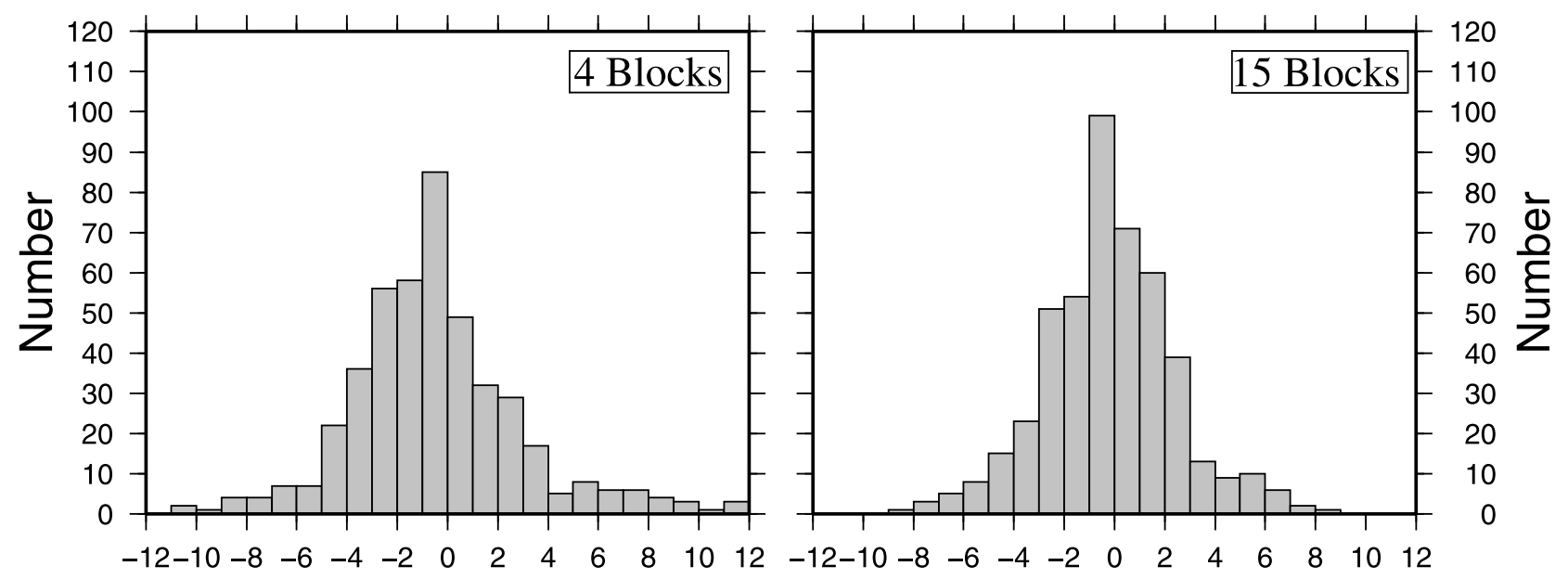

Misfit $\mathrm{mm} \mathrm{yr}^{-1}$

Misfit mm $\mathrm{yr}^{-1}$
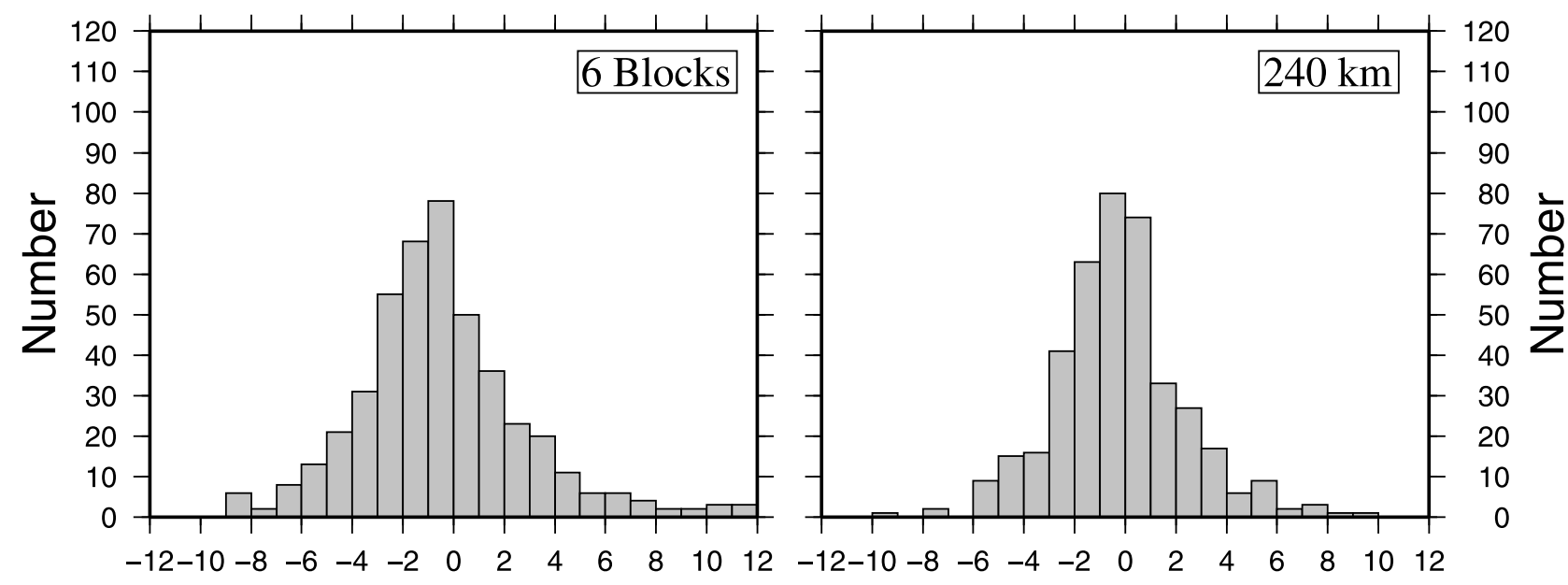

Misfit $\mathrm{mm} \mathrm{yr}^{-1}$

Misfit $\mathrm{mm} \mathrm{yr}^{-1}$
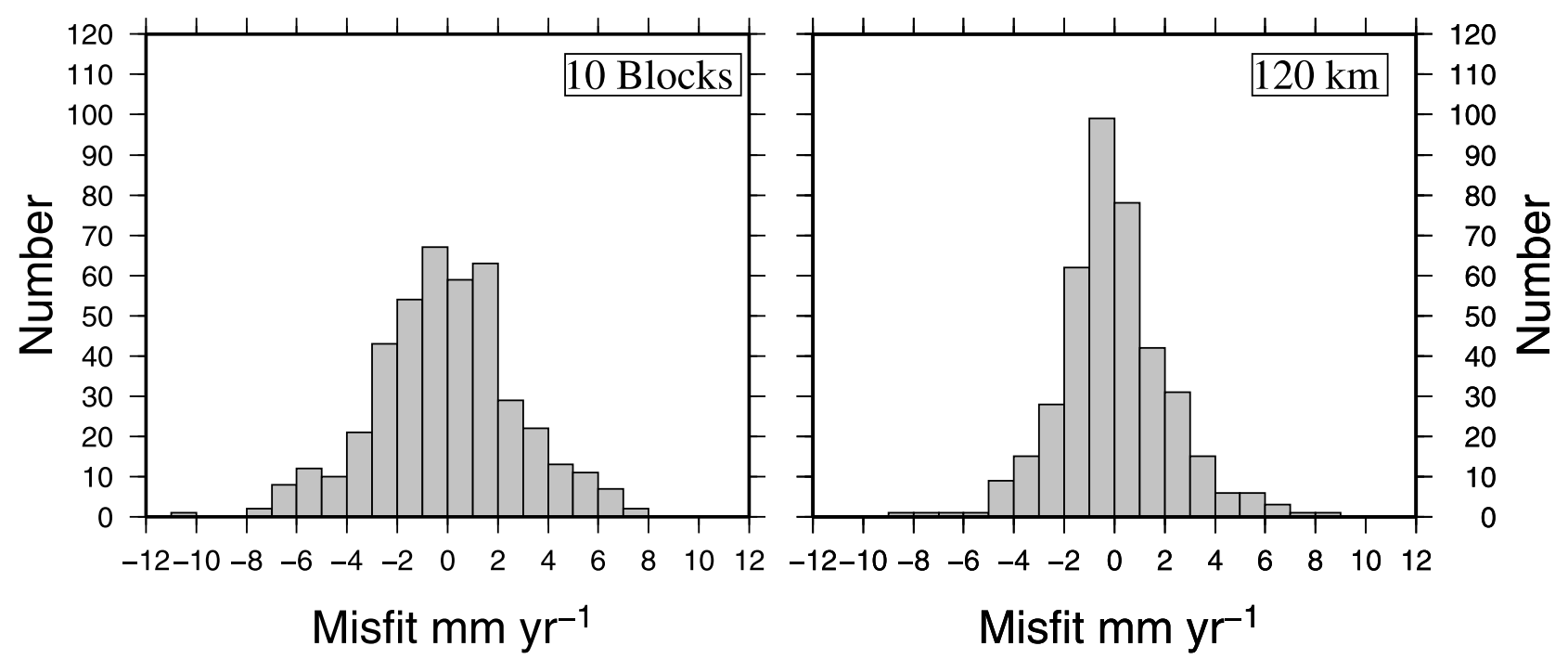

Figure 12. Distributions of the magnitudes of the misfits in the horizontal components of velocity between the observed velocities (Figure 3) and the block and continuous models for the Aegean discussed in the text. The 4-, 6-, 10-, and 15-block models refer to Figures 6a, 6b, 8a and 8b, respectively; misfits to the $120 \mathrm{~km}$ continuous model are shown in Figure 10; the $240 \mathrm{~km}$ continuous model is not illustrated. 

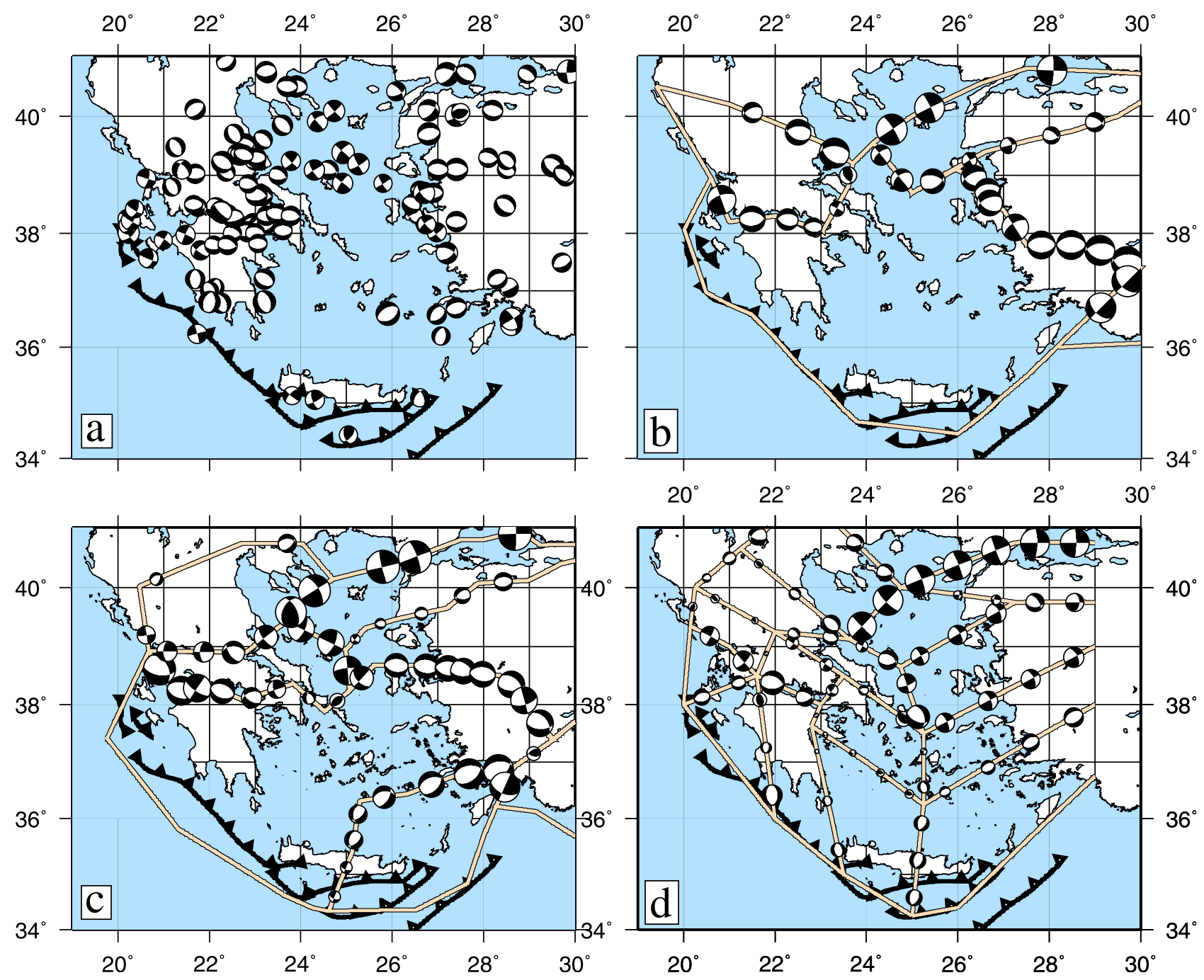

Figure 13. (a) Focal mechanisms of $M \geq 5.8$ earthquakes that have occurred within the continental crust of the Aegean over the past 120 years [Ambraseys and Jackson, 1990; Jackson and McKenzie, 1988; Shaw and Jackson, 2010]; earthquakes accommodating convergence in, and outboard of, the trenches are excluded. (b) Slip rates for boundary segments of the model of Nyst and Thatcher [2004] are depicted by focal mechanism representations, constructed using the dip and slip rates for each fault segment given by Nyst and Thatcher. Dip-slip faults dip at $45^{\circ}$, strike-slip faults are vertical. Strike-parallel and dip-parallel components of slip rate are converted into rake on the fault plane, and the area of each beachball is proportional to the rate of slip on the fault segment. (c) Same as Figure 13b except for the block model of Reilinger et al. [2006], using slip rates and fault dips given in their auxiliary material. (d) Same as Figure 13b except for the 15-block model shown in Figure 7.

faults, such as occurred in the 8 June 2008, M6.4, Achaia earthquake [Ganas et al., 2009; Shaw and Jackson, 2010].

[44] Block models also have the drawback, from the point of view of the Quaternary tectonics, that the block boundaries are clearly transient. For example, extensional deformation has migrated northward through the northern Peloponnese over the past few million years, with the major active faults along the south coast of the Gulf of Corinth only becoming active within the past $\sim 0.7 \mathrm{Myr}$ [e.g., Goldsworthy and Jackson, 2001; Ori, 1989; Rohais et al., 2007], while deformation has migrated across central Greece on three major normal-fault systems which have all been active within the past 5 Myr [Goldsworthy and Jackson, 2001].
Equally the southern Aegean region, which is now deforming slowly (Figure 11) or not at all (if it is part of a block), underwent almost $100 \%$ extensional strain since beginning of the present phase of extension in the Aegean region in Mio-Pliocene time [Angelier et al., 1982].

\subsection{Implications of Continuous Velocity Gradient Field for Aegean Tectonics and Seismic Hazard}

[45] We now consider the implications for the tectonics of the Aegean region of the field of velocity gradients calculated from the GPS data (Figure 11). We first address the dynamics of the region because, while a microplate model is by its very nature kinematic, and so requires no explanation 


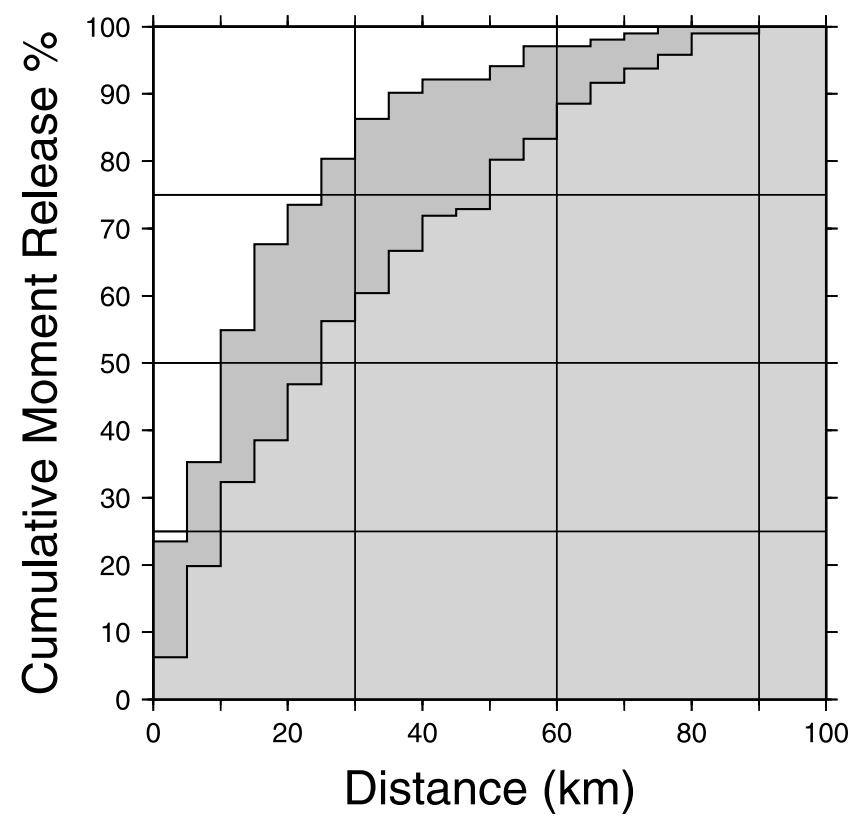

Figure 14. Cumulative histograms of the moment release in $M \geq 5.8$ earthquakes during the past 120 years as a function of distance of the earthquake from its nearest block boundary. Lighter shading is calculated using the block boundaries of Nyst and Thatcher [2004]; darker shading is for the boundaries of the 15-block model (Figure 7b). The distribution of the earthquakes is shown in Figure 5a.

for the relative motions, a model postulating a continuous field of deformation for the crust ought to provide a dynamical explanation for that deformation.

\subsubsection{Physical Explanation for the Velocity Gradient} Field

[46] The principal strain axes of Figure 11 show a pattern of generally north-south extension, though in the southern part of the region, where the extensional strain rates are lower, the principal axes of elongation swing round to become approximately parallel to the Hellenic Trench. In the northeastern Aegean, and around the northwestern termination of the Hellenic Trench, the extensional strain is augmented by a roughly equal amount of east-west contraction, producing two regions of horizontal simple shear. A full analysis of the dynamics of this deformation is beyond the scope of this paper, but we show here that its major features are consistent with the suggestion, made by a number of authors, that the Aegean behaves like a fluid subjected to an extensional boundary condition at its southern and southwestern boundaries, where it is bordered by ocean floor with low surface elevation [e.g., Hatzfeld et al., 1997a; Le Pichon, 1982; McKenzie, 1972, 1978b; Sonder and England, 1989].

[47] In what follows, we assume an Airy model for isostatic compensation, and follow England and McKenzie [1982] in estimating the distribution of gravitational potential energy (GPE) of the region from surface height. The difference, $\Gamma$, in GPE between a reference column of lithosphere, crustal thickness, $S_{0}$, and surface elevation zero, and a piece of lithosphere of surface height $h$ and crustal thickness $S$, is

$$
\begin{aligned}
\Gamma & =\frac{g \rho_{c}\left(1-\rho_{c} / \rho_{m}\right)\left(S^{2}-S_{0}^{2}\right)}{2} \\
& =\frac{g \rho_{c} h\left(S+S_{0}\right)}{2} \\
h & =\left(S-S_{0}\right)\left(1-\rho_{c} / \rho_{m}\right),
\end{aligned}
$$

where $g$ is the acceleration due to gravity, and $\rho_{c}$ and $\rho_{m}$ are the densities of crust and mantle, respectively; we neglect the differences between oceanic and continental crust for this simple calculation. The units of $\Gamma$ are $\mathrm{N} \mathrm{m}^{-1}$, or joules per unit surface area.

[48] This procedure gives us only an approximation to the GPE, because it is likely that lithospheric extension has

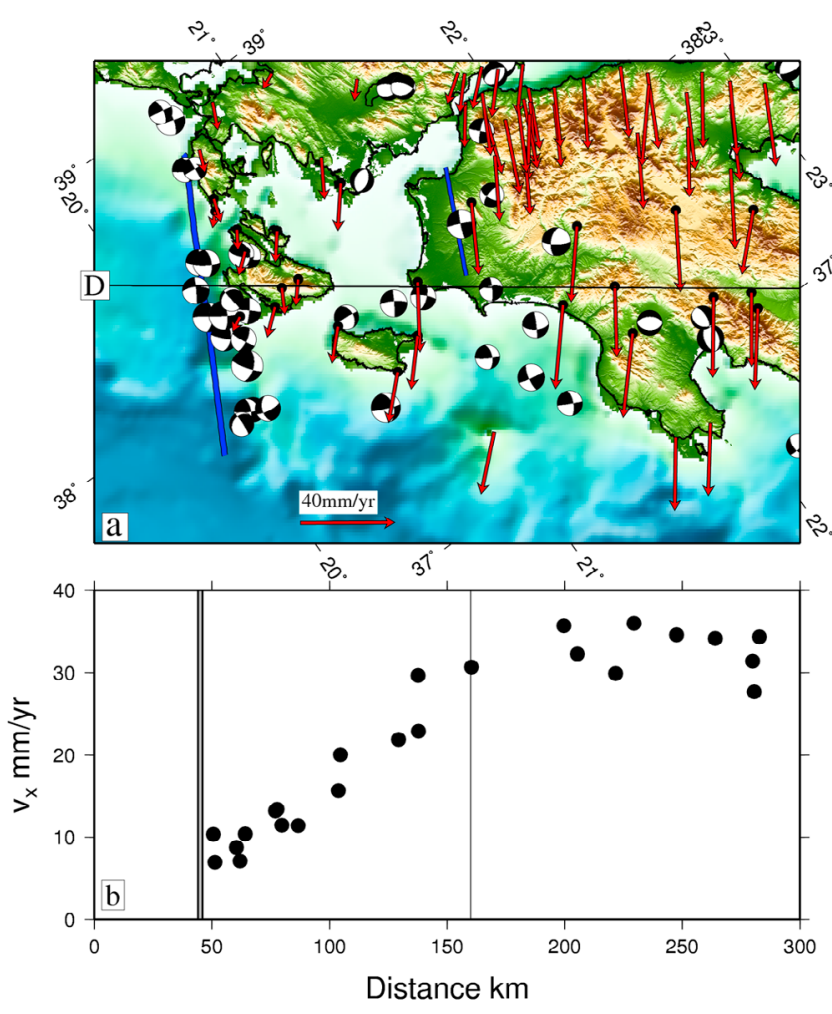

Figure 15. Distributed shear in western Greece. (a) Focal mechanisms of earthquakes within the overriding plate [Shaw and Jackson, 2010] and GPS velocities of this study. Black circles show sites within $50 \mathrm{~km}$ of profile line D (Figure 4d). Thick blue line represents location of Kefalonia strike-slip fault [Louvari et al., 1999]; thinner blue line represents the location of aftershocks to the M6.4, Achaia earthquake Ganas et al. [2009]. (b) The component of velocity perpendicular to the profile ( $x$ direction of Figure 3 ) for sites within $50 \mathrm{~km}$ of line D. Vertical bar indicates the crossing of the profile by the Kefalonia fault; thin vertical line indicates the projection onto this profile of the line of aftershocks to the Achaia earthquake. Horizontal scale matches that of Figure 15a. 


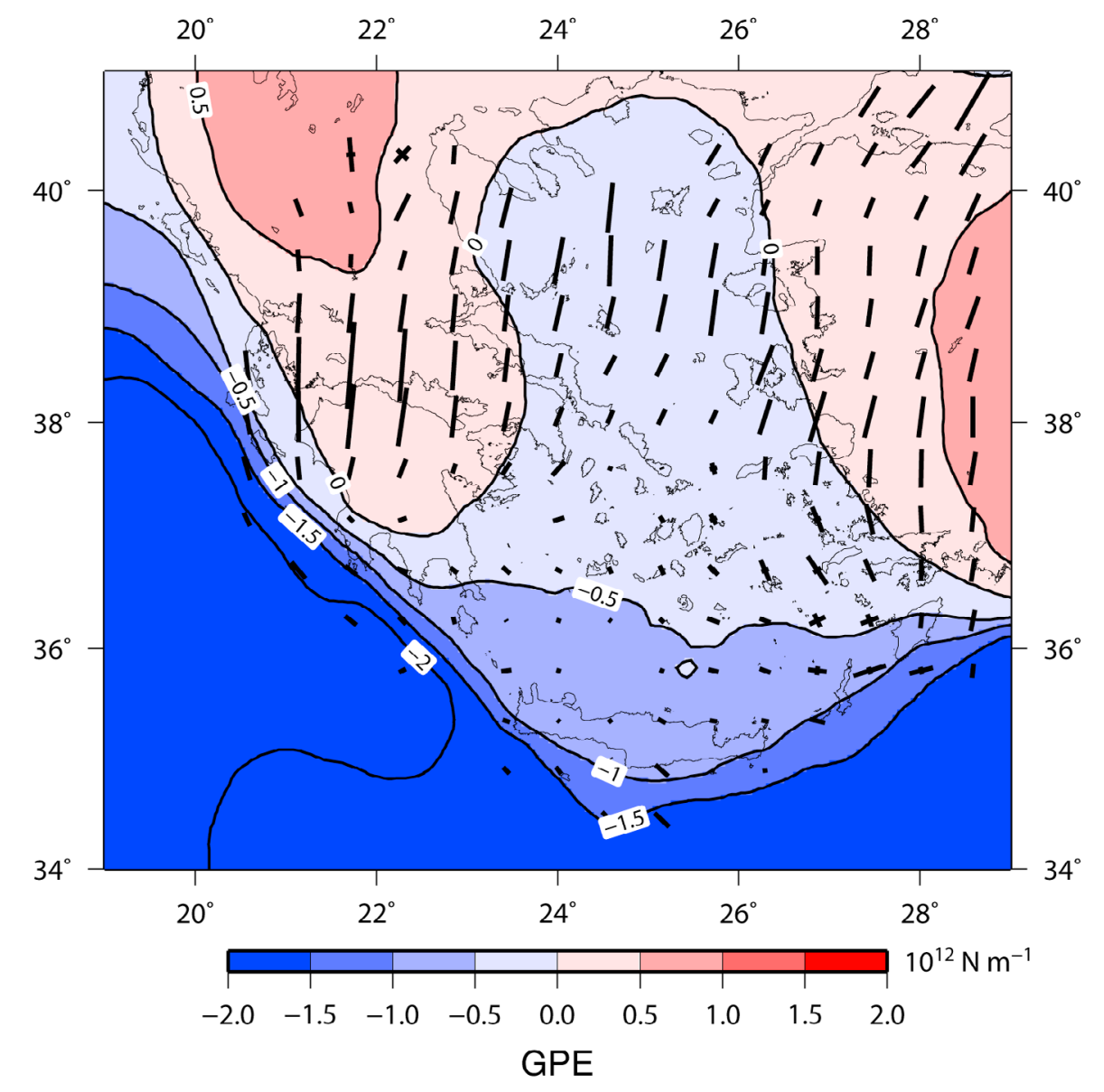

Figure 16. Principal horizontal extensional axes of the velocity gradient field shown in Figure 11, superimposed on the estimated gravitational potential energy (GPE) of the lithosphere of the region (see equation (2)). Densities of crust and mantle are 2800 and $3300 \mathrm{~kg} \mathrm{~m}^{-3}$, respectively, and the contours of GPE are in units of $10^{12} \mathrm{~N} \mathrm{~m}^{-1}$. Topography, and hence GPE, are smoothed with a Gaussian filter of width $200 \mathrm{~km}$.

perturbed the density structure below the crust [McKenzie, 1978a]; use of geoid anomalies to estimate GPE [Haxby and Turcotte, 1978] is ruled out because of the likely contribution of the slab to the geoid. With this approximation, the distribution of GPE in the eastern Mediterranean (relative to a reference column that has crustal thickness of $30 \mathrm{~km}$ ) varies between +1 and $-2 \times 10^{12} \mathrm{~N} \mathrm{~m}^{-1}$ (Figure 16). The sharp drop in GPE of $\sim 2 \times 10^{12} \mathrm{~N} \mathrm{~m}^{-1}$ at the southwest and southeast of the Aegean, is equivalent to a boundary condition of tensional deviatoric stress applied to the continental lithosphere to its north [e.g., Hatzfeld et al., 1997a; Le Pichon, 1982; McKenzie, 1972].

[49] England et al. [1985] gave approximate analytical solutions for the velocity distribution within a sheet of fluid subjected to such a boundary condition, and showed that velocities in the interior of the sheet are aligned perpendicular to the boundary and die out, in the direction perpendicular to the boundary, on a length scale that is comparable with the length of that boundary. Such a velocity distribution produces principal axes of elongation (in the case of an extensional boundary) that are also perpendicular to the boundary. The length of the extensional boundary to the Aegean, from the northwest Peloponnese to Rhodes, is about $800 \mathrm{~km}$, or about $600 \mathrm{~km}$ along a great circle joining its ends, and this is approximately equal to the $\mathrm{N}-\mathrm{S}$ extent of the Aegean extensional domain (Figure 1). We therefore suggest that the predominance of $\mathrm{N}-\mathrm{S}$ axes of principal elongation in the geodetic strain field of the Aegean reflects the influence of a tensional boundary condition along the southern and southwestern boundaries to the region.

[50] Two other features of the velocity gradient field require more than the extensional boundary condition alone to explain them. First, the motion of Turkey adds a westward component of velocity (relative to Eurasia) across the region, which causes the dextral shear and clockwise rotation from the north Aegean to the west of the Gulf of Corinth (Figure 11b). Second, the rate of extension in the Aegean south of about $36.5^{\circ} \mathrm{N}$ is significantly lower than in mainland Greece and western Turkey; this observation may be explained by the fact that the GPE in the southern Aegean is substantially lower than in mainland Greece and Turkey (Figure 16); the region is therefore subjected to a 
compressional deviatoric stress from the north, which counteracts the extensional deviatoric stress due to the southern boundary.

\subsubsection{Earthquakes and Coherent Strain Rate Field}

[51] If the earthquakes and active faulting in a region are to accommodate a given field of strain rate, then they must obey a few simple rules. With the assumption that one principal axis of strain rate is vertical, the faulting required to take up a regional velocity gradient field consists of dipslip faults striking perpendicular to one horizontal principal axis of strain rate, and strike-slip faults at an angle to that axis which depends upon their effective coefficient of friction [Houseman and England, 1986, Appendix]. This argument is related to that of Kostrov [1974], who showed that if all of the strain of a region of volume is released in earthquakes, then the components of the strain rate tensor are directly related to the summed moments of the earthquakes. However, whereas Kostrov's method involves averaging earthquakes over a large volume, with the inevitability that the result will be dominated by the largest earthquake, the argument of Houseman and England [1986] predicts the relation to the strain rate field of all earthquakes individually, irrespective of their size.

[52] Accommodation of the distributed extensional deformation of the Aegean (Figure 11) requires normal faults striking perpendicular to the principal axes of horizontal elongation, and strike-slip faults at between $45^{\circ}$ (for effectively frictionless faults) and $60^{\circ}$ (for faults with an effective coefficient of friction of 0.6 ) from those axes. The equivalent statement for the $\mathrm{T}$ axes of earthquakes is that for normal-faulting earthquakes they should be parallel to the principal axes of horizontal elongation, while for strike-slip earthquakes they should be parallel to those axes, for effectively frictionless faults, or up to $15^{\circ}$ away, for faults with effective coefficients of friction up to 0.6 [Molnar et al., 1973; Houseman and England, 1986, Appendix].

[53] We examine all the earthquakes of $M \geq 5.8$ that have occurred in the region over the past 120 years [Ambraseys and Jackson, 1990; Jackson and McKenzie, 1988; Shaw and Jackson, 2010]. We also examine likely intraplate earthquakes for the region from the Global CMT catalog (http://www.globalcmt.org); for this purpose, we choose from the catalog those normal- or strike-slip-faulting earthquakes in the region that have hypocenters shallower than $34 \mathrm{~km}$. The total data set consists of 223 focal mechanisms of earthquakes with magnitudes between 5 and 7.4.

[54] The mean misfit between the orientations of the $\mathrm{T}$ axes of the earthquakes and of the axes of principal elongation in the strain rate field is $22^{\circ}$ (Figure 17); there is no relation between fault type and misfit in orientations. Given that the orientation of fault planes in focal mechanisms, and of principal axes in moment tensors, are usually uncertain by at least $10^{\circ}$, this alignment between the geodetic velocity gradients and the orientations of $\mathrm{T}$ axes, regardless of whether the earthquake is large or small, or of whether it lies close to a block boundary, suggests that the faults within the upper crust of the region are taking up a coherent field of deformation [see also England, 2003].

[55] If crustal deformation of the region does, indeed, reflect an underlying coherent field of deformation then we should further expect that the distribution of moment release in earthquakes would reflect the regional distribution of strain rate. We express the geodetic strain rate in terms of its second invariant,

$$
\dot{E}=\left(\dot{\varepsilon}_{i j} \dot{\varepsilon}_{i j} / 2\right)^{\frac{1}{2}}
$$

where

$$
\begin{gathered}
\dot{\varepsilon}_{i j}=\frac{1}{2}\left(\frac{\partial v_{i}}{\partial x_{j}}+\frac{\partial v_{j}}{\partial x_{i}}\right), \\
\dot{\varepsilon}_{z z}=-\left(\frac{\partial v_{x}}{\partial x}+\frac{\partial v_{y}}{\partial y}\right), \\
\dot{\varepsilon}_{x z}=\dot{\varepsilon}_{y z}=0 .
\end{gathered}
$$

The subscripts $i, j$ on the components of velocity, $v$, and strain rate $\dot{\varepsilon}$, refer to the $x, y, z$ directions, with $z$ vertical, and equation (6) expresses the incompressibility of the medium. The quantity $\dot{E}$ is derived directly from the velocity gradients, using the technique described in section 3.2, with spatial resolution $\alpha=120 \mathrm{~km}$.

[56] There is a clear qualitative relation between the distribution of $M \geq 5.8$ earthquakes of the past 120 years and the scalar strain rate of the smoothly varying velocity gradient field, with earthquakes being clustered within regions of higher strain rate (Figure 18). To quantify this relationship, we calculated the second invariant of the strain rate in $25 \times 25 \mathrm{~km}$ boxes, and summed the scalar moments of the earthquakes (if any) within each box. Ordering the boxes in ascending order of strain rate shows that over $90 \%$ of the moment release took place within areas where the strain rate

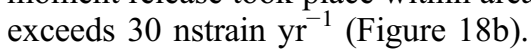

[57] We therefore disagree with the conclusion of Nyst and Thatcher [2004] that the earthquake activity and seismic hazard of the Aegean region are localized near the boundaries of a few (4) microplates. Approximately 50\% of the moment release in the past 120 years took place more than 30 kilometers from those boundaries (Figure 14); indeed some of the largest earthquakes in the Aegean during the past 120 years (e.g., the 1956 Amorgos earthquake) took place on faults that are far from the boundaries of these microplates, or on faults that are almost perpendicular to proposed block boundaries (for example, the 1894 Atalandi earthquakes).

[58] The repeat time between earthquakes on the faults of this region is likely to be hundreds to a few thousand years [e.g., Collier et al., 1998; Koukouvelas and Stamatopoulos, 2001; Pantosti et al., 2004; Kokkalas et al., 2007]; hence we cannot, solely from the 120 year instrumental record, rule out the microplate model as a basis for assessment of seismic hazard. Figure 11 suggests, however, that it would be unwise to overlook the information about seismic hazard that is contained in the continuous strain rate field.

\subsubsection{Active Faulting and Coherent Strain Rate Field}

[59] The major active normal faults of the region show displacements of order one or more kilometers which, coupled with repeat times of several hundred years between earthquakes having slips of order a meter, imply that the current systems have been active for the past 0.5 to $1 \mathrm{Myr}$. 


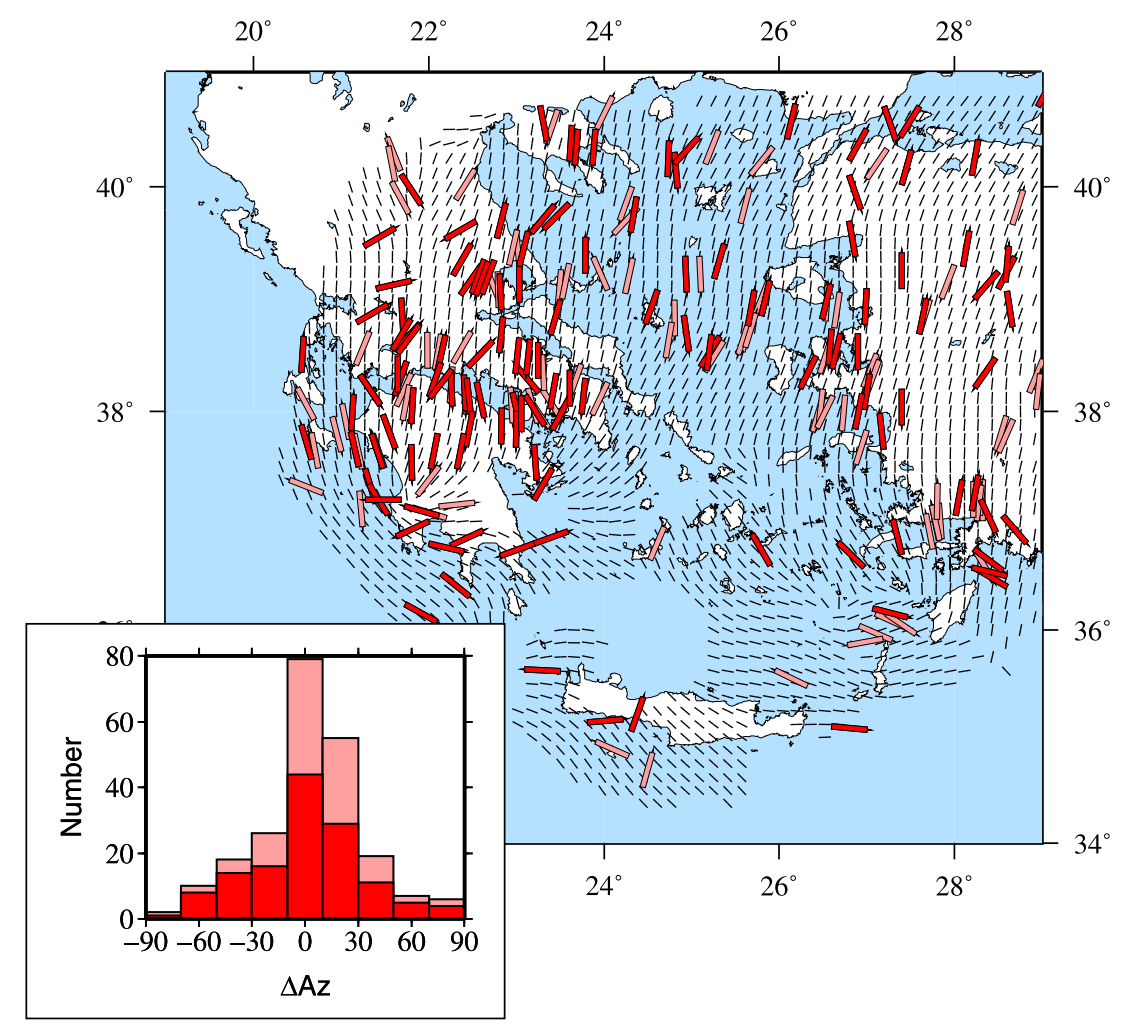

Figure 17. Grey bars show orientations of the principal horizontal extensional axes of the $120 \mathrm{~km}$ resolution strain rate field shown in Figure 11; dark red bars show the orientations of the $T$ axes of $M \geq 5.8$ earthquakes of the past 120 years for which reliable focal mechanisms could be obtained [Ambraseys and Jackson, 1990; Jackson and McKenzie, 1988; Shaw and Jackson, 2010]; lighter red bars show the orientations of the T axes of earthquakes $M<5.8$ from the Global CMT catalog (see text). Inset histogram shows the differences in orientation between the $T$ axes of the earthquakes and the principal horizontal extensional axis of the velocity field calculated at the location of the earthquake; lighter shading represents all earthquakes shown; darker shading represents the $M \geq 5.8$ earthquakes.

This finite strain is consistent with the instantaneous velocity gradient field (Figure 19). The normal-fault systems are all aligned roughly perpendicular to the principal axes of elongation in the geodetic velocity field (as has previously been noted, for example, by Davies et al. [1997] and Hollenstein et al. [2008]) and the major strike-slip faults lie at approximately $45^{\circ}$ to those axes (Figure 19). This is the relationship expected if faulting in the upper crust accommodates a coherent strain rate field with low effective coefficient on faults (see section 4.2.2 and Houseman and England [1986, Appendix]).

[60] Two other prominent aspects of the faulting can also be explained if it is assumed that the kinematics of the brittle upper crust are controlled by the dynamics of the ductile lithosphere beneath it. First, a number of analytical, numerical, and physical experiments on the dynamics of extension have shown that a rheologically layered lithosphere exhibits instabilities that grow into strain concentrations whose horizontal length scale depends on the rheological properties [e.g., Fletcher and Hallet, 1983; Hatzfeld et al., 1997a; Heimpel and Olson, 1996; Zuber and Parmentier, 1986]. Such instabilities may focus deformation into the continuous systems of faults that are observed in Greece [Goldsworthy et al., 2002]. Second, the migration of the fault systems with time [e.g., Goldsworthy and Jackson, 2001; Jackson, 1999] may be explained by the growth of such instabilities and/or by rapid rates of rotation about horizontal axes (or, for example in central Greece, about vertical axes: Figure 11) that can change the orientation of faults with respect to principal axes of strain rate by tens of degrees within a few million years.

\section{Conclusions}

[61] The velocities of 254 sites in the Aegean region, which we report here, are inconsistent with models for the tectonics of Greece and the Aegean that divide the region up into a small number of microplates [e.g., Nyst and Thatcher, 2004]. Rigid blocks with linear dimension $\sim 400 \mathrm{~km}$ or greater misfit the observed velocities by up to $15 \mathrm{~mm} \mathrm{yr}^{-1}$ (4-5 $\mathrm{mm} \mathrm{yr}^{-1} \mathrm{RMS}$ ), and the distributions of active faults (Figure 5a) and large earthquakes (Figure 5b) show that deformation is required in the interiors of such blocks.

[62] Decreasing the size of the blocks, and thereby increasing their number, improves the fit of block models to the observations. The velocities we report here can be fit to within about $2-3 \mathrm{~mm} \mathrm{yr}^{-1}$ RMS by the relative motions of 10 or more rigid blocks that are of scale $\sim 1-200 \mathrm{~km}$ on a 

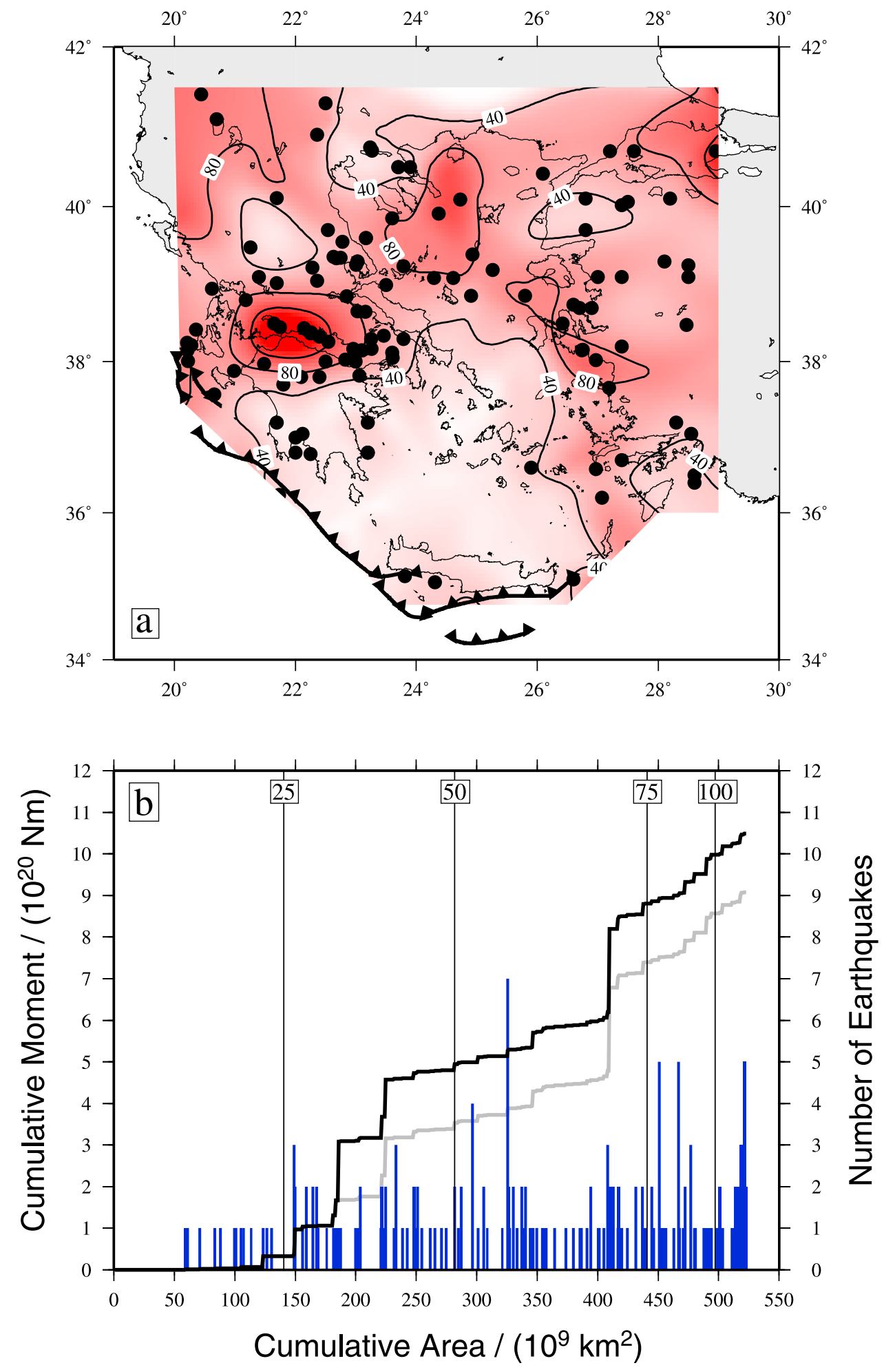

Figure 18. (a) Contours of the second invariant (equation (4)) of the strain rate tensor illustrated in Figure 11, in units of nanostrain per year. Dots show the epicenters of $M \geq 5.8$ earthquakes during the past 120 years [Ambraseys and Jackson, 1990; Jackson and McKenzie, 1988; Shaw and Jackson, 2010]. (b) Cumulative moment release from the earthquakes shown in Figure 18a plotted against cumulative area for $25 \times 25 \mathrm{~km}$ boxes (see text); black line is for all earthquakes, grey line excludes the largest earthquake within the Aegean in the past 120 years, the $M=7.4,9$ July 1956, Amorgos earthquake. Blue vertical lines show the number of earthquakes occurring within each box. Black vertical lines relate the cumulative area to the strain rate distribution: for example, about $1.4 \times 10^{11} \mathrm{~km}^{2}$ of the region are straining less rapidly than 25 nstrain $\mathrm{yr}^{-1} ; 2.8 \times 10^{11} \mathrm{~km}^{2}$ are straining less rapidly than $50 \mathrm{nstrain} \mathrm{yr}^{-1}$, and so on. 


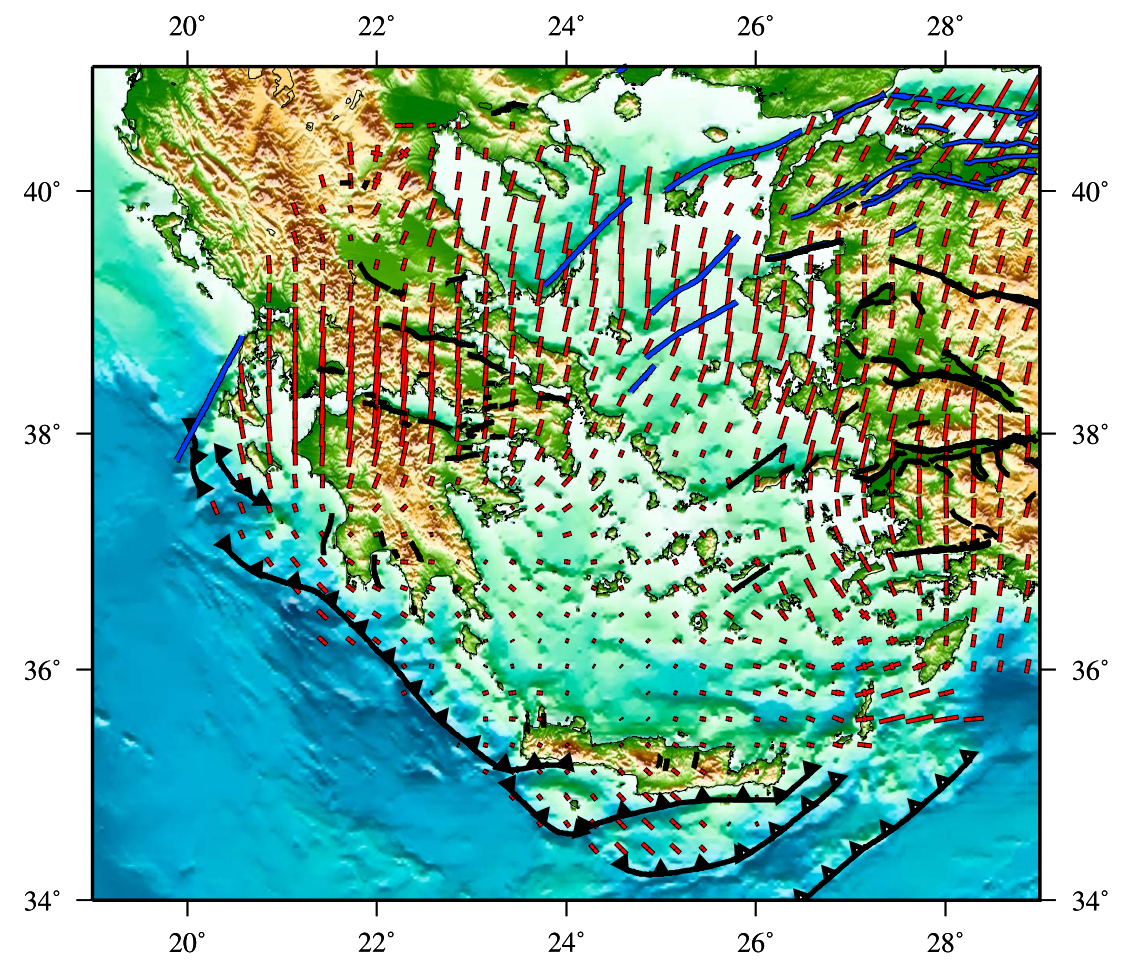

Figure 19. Orientations of active faults and of principal axes in the strain rate field. Red bars show orientations of the principal horizontal extensional axes of the $120 \mathrm{~km}$ resolution strain rate field shown in Figure 11. The symbols for faults are as in Figure 5b, except that the normal faults shown are only those thought to be active, on the basis either of historical seismicity or the existence of Quaternary fault scarps.

side (e.g., Figures 7 and 8). These velocities are fit equally well by a field of velocity gradients that is locally uniform on the scale of 100-200 km but varies smoothly on larger scales, though such a field underestimates the strain rates in the western Gulf of Corinth (Figure 11).

[63] Although continuous and block models fit the GPS velocities comparably well, the continuously varying field of velocity gradients offers the advantage of explaining the locations of, and sense of slip on, the major faults and earthquakes of the region. Ninety percent of the moment release in earthquakes of the past hundred years took place

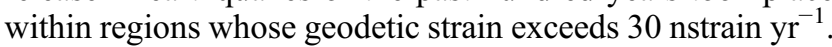
The $\mathrm{T}$ axes of the earthquakes are aligned with the axes of principal horizontal extension in the velocity field, irrespective of their magnitudes, or of whether they lie near to or far from postulated block boundaries. Finally, the orientations of the major normal faults are aligned perpendicular to the principal extensional axes of the geodetic strain rate field. These are the relationships expected if the lithosphere acts like a continuous medium, with the upper crust releasing its strain by slip on faults. We agree with previous authors who have suggested that the extension of the Aegean region (which is clearly expressed in the seismicity, the active faulting, and the Quaternary geomorphology, as well as in the geodesy) is explained by the difference in gravitational potential energy between the continental lithosphere of the Greece and Turkey and the oceanic lithosphere to the south and southwest of the region [e.g., Davies et al., 1997;
Hatzfeld et al., 1997a; Le Pichon, 1982; Le Pichon et al., 1995; McKenzie, 1972].

[64] Acknowledgments. This work has been supported by the Natural Environment Research Council through grant NER/A/S/2001/01607 and by funding of the Centre for Modeling of Earthquakes and Tectonics (COMET). M.F. is grateful to Exeter College, Oxford, for an Amelia Jackson studentship, which supported him during this work. We are grateful to a large number of staff and students at the National Technical University of Athens, the Massachusetts Institute of Technology, the Universities of Oxford and Newcastle, and the Institut de Physique du Globe, Paris, for their help in the GPS campaigns; in addition to those acknowledged in the original reports of those campaigns, we particularly thank P. Clarke, J. Hyde, P. Jackson, M. Moore, C. Raptakis, and A. Wright. We are grateful to Robert Reilinger for a long-running exchange of ideas about the data presented in this paper and for his comments on an early draft of the manuscript. We thank B. Shaw and J. Jackson for sharing their data in advance of publication. We also thank W. Thatcher and M. Nyst for several discussions about their work on the problems discussed here. We thank A. Ganas and W. Thatcher for reviews. The figures were made using GMT [Wessel and Smith, 1998].

\section{References}

Altamimi, Z., X. Collilieux, J. Legrand, B. Garayt, and C. Boucher (2007), ITRF2005: A new release of the International Terrestrial Reference Frame based on time series of station positions and Earth Orientation Parameters, J. Geophys. Res., 112, B09401, doi:10.1029/2007JB004949.

Ambraseys, N., and J. Jackson (1990), Seismicity and associated strain of central Greece between 1890 and 1988, Geophys. J. Int., 101(3), 663-708, doi:10.1111/j.1365-246X.1990.tb05577.x.

Ambraseys, N., C. Melville, and R. D. Adams (1994), The Seismicity of Egypt, Arabia and the Red Sea: A Historical Review, doi:10.1017/ CBO9780511524912, Cambridge Univ. Press, Cambridge, U. K.

Angelier, J., N. Lyberis, X. L. Pichon, E. Barrier, and P. Huchon (1982),

The tectonic development of the Hellenic arc and the Sea of Crete: A 
synthesis, Tectonophysics, 86(1-3), 159-196, doi:10.1016/0040-1951 (82)90066-X

Avallone, A., P. Briole, and A. Agatza-Balodimou (2004), Analysis of eleven years of deformation measured by GPS in the Corinth Rift laboratory area, C. R. Acad. Sci. Geosci., 336, 301-311, doi:10.1016/j.crte. 2003.12.007.

Baker, C., D. Hatzfeld, H. Lyon-Caen, E. Papadimitriou, and A. Rigo (1997), Earthquake mechanisms of the Adriatic Sea and western Greece: Implications for the oceanic subduction-continental collision transition, Geophys. J. Int., 131(3), 559-594, doi:10.1111/j.1365-246X.1997. tb06600.x.

Barka, A. (1996), Slip distribution along the North Anatolian fault associated with the larger earthquakes of the period 1939 to 1967 , Bull. Seismol. Soc. Am., 86, 1238-1254.

Bernard, P., et al. (1997), The $\mathrm{M}_{s}=6.2$, June 15, 1995 Aigion earthquake (Greece): Evidence for low angle normal faulting in the Corinth rift, J. Seismol., 1(2), 131-150, doi:10.1023/A:1009795618839.

Billiris, H., et al. (1991), Geodetic determination of tectonic deformation in central Greece from 1900 to 1988, Nature, 350, 124-129, doi:10.1038/ $350124 \mathrm{a} 0$

Bird, P., and K. Piper (1980), Plane-stress finite-element models of tectonic flow in southern California, Phys. Earth Planet. Inter., 21, 158-175, doi:10.1016/0031-9201(80)90067-9.

Bourne, S., P. England, and B. Parsons (1998), The motion of crustal blocks driven by flow of the lower lithosphere and implications for slip rates of continental strike-slip faults, Nature, 391, 655-659, doi:10.1038/ 35556

Briole, P., et al. (2000), Active deformation of the Corinth rift, Greece: Results from repeated Global Positioning System surveys between 1990 and 1995, J. Geophys. Res., 105(B11), 25,605-25,625, doi:10.1029/ 2000JB900148.

Clarke, P., et al. (1997), Geodetic estimate of seismic hazard in the Gulf of Korinthos, Geophys. Res. Lett., 24, 1303-1306, doi:10.1029/ 97GL01042.

Clarke, P. J., et al. (1998), Crustal strain in central Greece from repeated GPS measurements in the interval 1989-1997, Geophys. J. Int., 135(1), 195-214, doi:10.1046/j.1365-246X.1998.00633.x.

Collier, R., D. Pantosti, G. D'Addezio, P. D. Martini, E. Masana, and D. Sakellariou (1998), Paleoseismicity of the 1981 Corinth earthquake fault: Seismic contribution to extensional strain in central Greece and implications for seismic hazard, J. Geophys. Res., 103(B12), 30,00130,019, doi:10.1029/98JB02643.

Davies, R., P. England, B. Parsons, H. Billiris, D. Paradissis, and G. Veis (1997), Geodetic strain of Greece in the interval 1892-1992, J. Geophys. Res., 102(B11), 24,571-24,588, doi:10.1029/97JB01644.

England, P. (2003), The alignment of earthquake T-axes with the principa axes of geodetic strain in the Aegean region, Turkish J. Earth Sci., 12 , 47-53.

England, P., and J. Jackson (1989), Active deformation of the continents, Annu. Rev. Earth Planet. Sci., 17, 197-226, doi:10.1146/annurev. ea.17.050189.001213.

England, P., and D. McKenzie (1982), A thin viscous sheet model for continental deformation, Geophys. J. R. Astron. Soc., 70, 295-321.

England, P., and D. McKenzie (1983), Correction to a thin viscous sheet model for continental deformation, Geophys. J. R. Astron. Soc., 73, 523-532.

England, P., G. Houseman, and L. Sonder (1985), Length scales for continental deformation in convergent, divergent and strike-slip environments: Analytical and approximate solutions for a thin viscous sheet model, J. Geophys. Res., 90(B5), 3551-3557, doi:10.1029/JB090iB05p03551.

Fletcher, R., and B. Hallet (1983), Unstable extension of the lithosphere: a mechanical model for basin-and-range structure, J. Geophys. Res., 88, 7457-7466, doi:10.1029/JB088iB09p07457.

Ganas, A., and T. Parsons (2009), Three-dimensional model of Hellenic Arc deformation and origin of the Cretan uplift, J. Geophys. Res., 114 B06404, doi:10.1029/2008JB005599.

Ganas, A., E. Serpelloni, G. Drakatos, M. Kolligri, I. Adamis, C. Tsimi, and E. Batsi (2009), The $\mathrm{M}_{w}$ 6.4 SW-Achaia (western Greece) earthquake of 8 June 2008: Seismological, field, GPS observations, and stress modeling, J. Earthquake Eng., 13(8), 1101-1124, doi:10.1080/ 13632460902933899.

Goldsworthy, M., and J. A. Jackson (2000), Active normal fault evolution and interaction in Greece revealed by geomorphology and drainage patterns, J. Geol. Soc., 157, 967-981, doi:10.1144/jgs.157.5.967.

Goldsworthy, M., and J. Jackson (2001), Migration of activity within normal fault systems: Examples from the Quaternary of mainland Greece, J. Struct. Geol., 23(2-3), 489-506, doi:10.1016/S0191-8141(00)00121-8.
Goldsworthy, M., J. Jackson, and J. Haines (2002), The continuity of active fault systems in Greece, Geophys. J. Int., 148(3), 596-618, doi:10.1046/ j.1365-246X.2002.01609.x

Hatzfeld, D., et al. (1995), The Kozani-Grevena (Greece) earthquake of May $13,1995, \mathrm{M}_{s}=6.6$. Preliminary results of a field multidisciplinary survey, Seismol. Res. Lett., 66, 61-70.

Hatzfeld, D., J. Martinod, G. Bastet, and P. Gautier (1997a), An analog experiment for the Aegean to describe the contribution of gravitational potential energy, J. Geophys. Res., 102(B1), 649-659, doi:10.1029/ 96JB02594.

Hatzfeld, D., et al. (1997b), The Kozani-Grevena (Greece) earthquake of 13 May 1995 revisited from a detailed seismological study, Bull. Seismol. Soc. Am., 87(2), 463-473.

Hatzfeld, D., V. Karakostas, M. Ziazia, I. Kassaras, E. Papadimitriou, K. Makropoulos, N. Voulgaris, and C. Papaioannou (2000), Microsesmicity and faulting geometry in the Gulf of Corinth (Greece), Geophys. J. Int., 141, 438-456, doi:10.1046/j.1365-246x.2000.00092.x.

Haxby, W. F., and D. L. Turcotte (1978), On isostatic geoid anomalies, J. Geophys. Res., 83(B11), 5473-5478, doi:10.1029/JB083iB11p05473. Heimpel, M., and P. Olson (1996), A seismodynamical model of lithosphere deformation: Development of continental and oceanic rift networks, J. Geophys. Res., 101(B7), 16,155-16,176, doi:10.1029/ 96JB00168.

Herring, T. A., R. W. King, and S. C. McClusky (2009), Introduction to GAMIT/GLOBK Release 10.35, Dep. of Earth, Atmos. and Planet, Sci., Mass. Inst. of Technol., Cambridge. (Available at http://wwwgpsg.mit.edu/ simon/gtgk/index.htm)

Hollenstein, C., M. D. Müller, A. Geiger, and H.-G. Kahle (2008), Crustal motion and deformation in Greece from a decade of GPS measurements, 1993-2003, Tectonophysics, 449(1-4), 17-40, doi:10.1016/j.tecto. 2007.12.006.

Houseman, G., and P. England (1986), Finite strain calculations of continental deformation: 1 . Method and general results for convergent zones, J. Geophys. Res., 91(B3), 3651-3663, doi:10.1029/JB091iB03p03651.

Jackson, J. (1999), Fault death: A perspective from actively deforming regions, J. Struct. Geol., 21, 1003-1010, doi:10.1016/S0191-8141(99) 00013-9.

Jackson, J., and D. P. McKenzie (1988), The relationship between plate motions and seismic moment tensors and the rate of active deformation in the Mediterranean and Middle East, Geophys. J. R. Astron. Soc., 93 $45-73$.

Jackson, J., A. Haines, and W. Holt (1995), The accommodation of ArabiaEurasia plate convergence in Iran, J. Geophys. Res., 100, 15,205-15,220, doi:10.1029/95JB01294.

Jackson, J. A., J. Gagnepain, G. Houseman, G. C. P. King, P. Papadimitriou, C. Soufleris, and J. Virieux (1982), Seismicity, normal faulting, and the geomorphological development of the Gulf of Corinth (Greece): The Corinth earthquakes of February and March 1981, Earth Planet. Sci. Lett., 57, 377-397, doi:10.1016/0012-821X(82)90158-3.

Kahle, H.-G., M. Cocard, Y. Peter, A. Geiger, R. Reilinger, A. Barka, and G. Veis (2000), GPS-derived strain field within the boundary zone of the Eurasian, African, and Arabian plates, J. Geophys. Res., 105(B10), 23,353-23,370, doi:10.1029/2000JB900238.

Kokkalas, S., S. Pavlides, I. Koukouvelas, A. Ganas, and L. Stamatopoulos (2007), Paleoseismicity of the Kaparelli fault (eastern Corinth Gulf): Evidence for earthquake recurrence and fault behaviour, Boll. Soc. Geol. Ital., 126, 387-395.

Kostrov, B. (1974), Seismic moment and energy of earthquakes, and seismic flow of rock, Izv. Acad. Sci. USSR Phys. Solid Earth, Engl. Transl., 97, 23-44.

Koukouvelas, I., and L. Stamatopoulos (2001), A palæoseismological and geoarchæological investigation of the Eliki fault, Gulf of Corinth, Greece, J. Struct. Archaeol., 113, 186-193.

Le Pichon, X. (1982), Land-locked oceanic basins and continental collision; the eastern Mediterranean as a case example, in Mountain Building Processes, edited by K. Hsü, pp. 129-146, Academic, London.

Le Pichon, X., N. Chamot-Rooke, S. Lallemant, R. Noomen, and G. Veis (1995), Geodetic determination of the kinematics of central Greece with respect to Europe: Implications for eastern Mediterranean tectonics, J. Geophys. Res., 100(B7), 12,675-12,690, doi:10.1029/95JB03170.

Louvari, E., A. Kiratzi, and B. Papazachos (1999), The Cephalonia transform fault and its extension to western Lefkada island (Greece), Tectonophysics, 308(1-2), 223-236, doi:10.1016/S0040-1951(99)00078-5.

Mandelbrot, B. B., and J. W. Van Ness (1968), Fractional Brownian motions, fractional noises and applications, SIAM Rev., 10(4), 422-437, doi: $10.1137 / 1010093$

McClusky, S., et al. (2000), Global Positioning System constraints on plate kinematics and dynamics in the eastern Mediterranean and Caucasus, J. Geophys. Res., 105(B3), 5695-5719, doi:10.1029/1999JB900351. 
McKenzie, D. (1970), Plate tectonics of Mediterranean region, Nature, 226(5242), 239-243, doi:10.1038/226239a0.

McKenzie, D. (1972), Active tectonics of the Mediterranean region, Geophys. J. R. Astron. Soc., 30(2), 109-185.

McKenzie, D. (1978a), Some remarks on the development of sedimentary basins, Earth Planet. Sci. Lett., 40(1), 25-32, doi:10.1016/0012-821X (78)90071-7.

McKenzie, D. (1978b), Active tectonics of the Alpine-Himalayan beltAegean Sea and surrounding regions, Geophys. J. R. Astron. Soc., 55(1), 217-254.

McKenzie, D., and J. Jackson (1983), The relationship between strain rates, crustal thickening, paleomagnetism, finite strain and fault movements within a deforming zone, Earth Planet. Sci. Lett., 65, 182-202, doi:10.1016/0012-821X(83)90198-X.

McKenzie, D., and J. Jackson (1986), A block model of distributed deformation by faulting, J. Geol. Soc., 143, 349-353, doi:10.1144/gsjgs. 143.2.0349.

Meade, B. J., and B. H. Hager (2005), Block models of crustal motion in southern California constrained by GPS measurements, J. Geophys. Res., 110, B03403, doi:10.1029/2004JB003209.

Meade, B. J., B. H. Hager, S. C. McClusky, R. E. Reilinger, S. Ergintav, O. Lenk, A. Barka, and H. Özener (2002), Estimates of seismic potential in the Marmara Sea region from block models of secular deformation constrained by Global Positioning System measurements, Bull. Seismol. Soc. Am., 92(1), 208-215, doi:10.1785/0120000837.

Meyer, B., R. Armijo, D. Massonnet, J. B. de Chabalier, C. Delacourt, J. C. Ruegg, J. Achache, P. Briole, and D. Papanastassiou (1996), The 1995 Grevena (northern Greece) earthquake: Fault model constrained with tectonic observations and SAR interferometry, Geophys. Res. Lett., 23(19), 2677-2680, doi:10.1029/96GL02389.

Molnar, P. (1988), Continental tectonics in the aftermath of plate tectonics, Nature, 335(6186), 131-137, doi:10.1038/335131a0.

Molnar, P., and H. Lyon-Caen (1988), Some simple physical aspects of the support, structure, and evolution of mountain belts, in Processes in Continental Lithospheric Deformation, edited by S. P. Clark Jr., B. C. Burchfiel, and J. Suppe, Spec. Pap. Geol. Soc. Am., 218, 179-207.

Molnar, P., T. Fitch, and F. Wu (1973), Fault plane solutions of shallow earthquakes and contemporary tectonics in Asia, Earth Planet. Sci. Lett. 19(2), 101-112, doi:10.1016/0012-821X(73)90104-0.

Nyst, M., and W. Thatcher (2004), New constraints on the active tectonic deformation of the Aegean, J. Geophys. Res., 109, B11406, doi:10.1029/ 2003JB002830.

Ori, G. (1989), Geologic history of the extensional basin of the gulf of Corinth (Miocene-Pliestocene), Geology, 17(10), 918-921, doi:10.1130/ 0091-7613(1989)017<0918:GHOTEB >2.3.CO;2.

Pantosti, D., P. D. Martini, D. Papanastassiou, F. Lemeille, N. Palyvos, and G. Stavrakakis (2004), Paleoseismological trenching across the Atalanti fault (central Greece): Evidence for the ancestors of the 1894 earthquake during the middle ages and roman times, Bull. Seismol. Soc. Am., 94(2), 531-549, doi:10.1785/0120020207.

Reilinger, R., et al. (2006), GPS constraints on continental deformation in the Africa-Arabia-Eurasia continental collision zone and implications for the dynamics of plate interactions, J. Geophys. Res., 111, B05411, doi:10.1029/2005JB004051.

Reilinger, R., S. McClusky, D. Paradissis, S. Ergintav, and P. Vernant (2010), Geodetic constraints on the tectonic evolution of the Aegean region and strain accumulation along the Hellenic subduction zone, Tectonophysics, 488, 22-30, doi:10.1016/j.tecto.2009.05.027.

Resor, P. G., D. D. Pollard, T. J. Wright, and G. C. Beroza (2005), Integrating high-precision aftershock locations and geodetic observations to model coseismic deformation associated with the 1995 Kozani-Grevena earthquake, Greece, J. Geophys. Res., 110, B09402, doi:10.1029/ 2004JB003263.

Rohais, S., S. Joannin, J.-P. Colin, J.-P. Suc, F. Guillocheau, and R. Eschard (2007), Age and environmental evolution of the syn-rift fill of the southern coast of the Gulf of Corinth (Akrata-Derveni region, Greece), Bull. Soc. Geol. Fr., 178, 231-243, doi:10.2113/gssgfbull.178.3.231.

Savage, J., and R. Burford (1973), Geodetic determination of relative plate motion in central California, J. Geophys. Res., 78, 832-845, doi:10.1029/ JB078i005p00832.

Shaw, B., and J. Jackson (2010), Earthquake mechanisms and active tectonics of the Hellenic subduction zone, Geophys. J. Int., 181(2), 966-984, doi:10.1111/j.1365-246X.2010.04551.x.

Shaw, B., et al. (2008), Eastern Mediterranean tectonics and tsunami hazard inferred from the AD 365 earthquake, Nat. Geosci., 1(4), 268-276, doi:10.1038/ngeo151.

Shen, Z., D. Jackson, and B. Ge (1996), Crustal deformation across and beyond the Los Angeles basin from geodetic measurements, J. Geophys. Res., 101(B12), 27,957-27,980, doi:10.1029/96JB02544.

Sonder, L. J., and P. C. England (1989), Effects of a temperature-dependent rheology on large-scale continental extension, J. Geophys. Res. 94(B6), 7603-7619, doi:10.1029/JB094iB06p07603.

Taymaz, T., J. Jackson, and D. McKenzie (1991), Active tectonics of the north and central Aegean Sea, Geophys. J. Int., 106(2), 433-490, doi:10.1111/j.1365-246X.1991.tb03906.x.

Veis, G., H. Billiris, B. Nakos, and D. Paradissis (1992), Tectonic strain in Greece from geodetic measurements, C. R. Acad. Sci. Athens, 67, $129-166$.

Vilotte, J., M. Daignières, and R. Madariaga (1982), Numerical modeling of intraplate deformation: Simple mechanical models of continental collision, J. Geophys. Res., 87(B13), 10,709-10,728, doi:10.1029/ JB087iB13p10709.

Wdowinski, S., Y. Bock, J. Zhang, P. Fang, and J. Genrich (1997), Southern California Permanent GPS Geodetic Array: Spatial filtering of daily positions for estimating coseismic and postseismic displacements induced by the 1992 Landers earthquake, J. Geophys. Res., 102(B8), 18,057-18,070, doi:10.1029/97JB01378.

Wessel, P., and W. H. F. Smith (1998), New, improved version of generic mapping tools released, Eos Trans. $A G U, 79,579$, doi:10.1029/ 98EO00426.

Williams, S. D. P. (2008), CATS: GPS coordinate time series analysis software, GPS Solut., 12(2), 147-153, doi:10.1007/s10291-007-0086-4.

Zhang, J., Y. Bock, H. Johnson, P. Fang, S. Williams, J. Genrich, S Wdowinski, and J. Behr (1997), Southern California Permanent GPS Geodetic Array: Error analysis of daily position estimates and site velocities, J. Geophys. Res., 102(B8), 18,035-18,055, doi:10.1029/97JB01380.

Zuber, M., and E. Parmentier (1986), Lithospheric necking-A dynamic model for rift morphology, Earth Planet. Sci. Lett., 77(3-4), 373-383, doi:10.1016/0012-821X(86)90147-0.

A. Avallone, Istituto Nazionale di Geofisica e Vulcanologia, Centro Nazionale Terremoti, Via di Ligna Murata 605, I-00143 Roma, Italy.

H. Billiris, D. Paradissis, and G. Veis, Higher Geodesy Laboratory, National Technical University, 9, Heroon Polytechniou Str., GR-15780 Zography, Athens, Greece.

P. Briole, Ecole Normale Supérieure, Laboratoire de Géologie, 24 Rue Lhomond, F-75005 Paris, France.

P. C. England, K. Palamartchouk, and B. E. Parsons, COMET, Department of Earth Sciences, University of Oxford, South Parks Road, Oxford OX13AN, UK. (philip.england@earth.ox.ac.uk)

M. A. Floyd, Department of Earth Sciences, University of California, Riverside, 900 University Ave., Riverside, CA 92521, USA.

S. McClusky, Department of Earth, Atmospheric, and Planetary Sciences, Massachusetts Institute of Technology, 77 Massachusetts Ave. Cambridge, MA 02139-4307, USA.

J.-M. Nocquet, CNRS-GéoAzur 250, University of Nice, Rue Albert Einstein, F-06560 Valbonne, France. 